\title{
Absence of Synthesis-Modulating Nerve Terminal Autoreceptors on Mesoamygdaloid and Other Mesolimbic Dopamine Neuronal Populations
}

\author{
Clinton D. Kilts, ${ }^{1,2}$ Carl M. Anderson, ${ }^{1}$ Timothy D. Ely, ${ }^{1}$ and J. Ken Nishita ${ }^{1}$ \\ Departments of ${ }^{1}$ Psychiatry and ${ }^{2}$ Pharmacology, Duke University Medical Center, Durham, North Carolina 27710
}

The present study sought to map the distribution of dopamine (DA) synthesis-modulating autoreceptors on DA nerve terminals innervating the amygdala and other limbic structures of the rat brain at a level of anatomic resolution (i.e., discrete component nuclei) commensurate with the functional organization of such structures. The biochemically estimated response of mesoamygdaloid and other limbic DA neuronal populations to conditions of minimal (gammabutyrolactone administration or surgical axotomy) and maximal (low-dose apomorphine administration) activation of nerve terminal DA autoreceptors was examined and compared to the response of mesostriatal and mesocortical DA neurons. In contrast to the caudate nucleus, nucleus accumbens, and olfactory tubercle, neither gammabutyrolactone (GBL) nor axotomy increased biochemically estimated DA synthesis (DOPA accumulation) in any of the amygdaloid nuclei, the anterior amygdaloid area, septal nuclei, or subdivisions of the interstitial (bed) nucleus of the stria terminalis. These results indicate that, simllar to the medial prefrontal cortex and median eminence, DA synthesis in mesoamygdaloid and other subcortical limbic DA neuronal populations is not under the regulatory influence of tonically active, nerve terminallocalized autoreceptors. Both GBL and axotomy increased DOPA accumulation in the anterior cingulate cortex, but not in allocortical projection fields. In contrast to the differential distribution of DA synthesis-modulating terminal autoreceptors, the end-product inhibition of tyrosine hydroxylase activity appears to be a ubiquitously expressed regulatory property of DA neurons. The decrease in DA metabolism produced by the administration of a low, presumably autoreceptor-selective, dose of apomorphine exhibited a DA neuronal population distribution distinctly unlike that of the aforementioned effects of GBL or axotomy on DOPA accumulation.

These results reinforce the DA neuronal population-selective distribution of synthesis-modulating autoreceptors and indicate that nerve terminal-localized autoreceptors are operative in regulating DA synthesis in only a minority of DAinnervated brain structures. Further, the demonstration of

\footnotetext{
Received Nov. 25, 1986; revised May 18, 1987; accepted May 21, 1987.

This work was supported by a Public Health Service grant from the National Institute of Mental Health (MH-39967). The authors gratefully acknowledge the efforts of Gail Atwater, Margaret Kasper, Michael Robinson, and Kathleen Krebs, and would like to thank Dr. Michael Bannon for his advice in conducting the axotomies.

Correspondence should be addressed to Dr. Clinton Kilts, Box 3833, Duke University, Medical Center, Durham, NC 27710.

Copyright (C) 1987 Society for Neuroscience $0270-6474 / 87 / 123961-15 \$ 02.00 / 0$
}

such autoreceptors is dependent upon the preparation, pharmacological tools, and functional endpoints chosen for study.

The amygdala is an assembly of nuclei (aggregations of cell bodies in the central nervous system) located in the temporallobes of the brains of mammals, and is central to every definition of the anatomical organization of the limbic system. The component nuclei of the amygdala exhibit a remarkably wide-ranging heterogeneity in their cytoarchitecture (Brodal, 1947; Millhouse and DeOlmos, 1981), biochemistry (Brownstein et al., 1974; Palkovits et al., 1974; Saavedra et al., 1974; Roberts et al., 1982; Shiosaka et al., 1983), function (Shibata et al., 1982; Siegel, 1984; Dunn and Whitener, 1986), pharmacology (Fekete et al., 1979), afferent and efferent neuronal projections (Ottersen and Ben-Ari, 1979; Ottersen, 1980, 1981, 1982), phylogeny (Humphrey, 1936; Stephan and Andy, 1977), and ontogeny (Ten Donkelaar et al., 1979; Bayer, 1980). Accumulated evidence supports a neuromodulator or neurotransmitter role for the putative neurotransmitter dopamine (DA) in the amygdala. The amygdala receives a demonstrated DA innervation from cell bodies located in the ventromedial mesencephalon (Ungerstedt, 1971; Fallon et al., 1978), a pathway usually considered to be part of the broadly defined mesolimbic or mesolimbocortical DA systems (Lindvall and Björklund, 1983). The local application of DA produces a neuroleptic-reversible inhibition of both spontaneously firing and glutamate-activated cells in the amygdala (Ben-Ari and Kelly, 1976). A responsive mechanism for neuronal DA release (Charriere et al., 1983), presynaptic sites for DA uptake (Javitch et al., 1985; Scatton et al., 1985), and the enzymatic machinery for DA synthesis (Saavedra and Zivin, 1976) and catabolism (Hirano et al., 1978) have been demonstrated in the amygdala. The presence of amygdaloid DA receptors has been inferred from the presence of a DA-sensitive adenylate cyclase (Clement-Cormier and Robison, 1977), binding sites labeled by radioactive DA ligands (Klemm et al., 1979; Boyson et al., 1986; Dawson et al., 1986; Dubois et al., 1986), and a phosphoprotein representing a molecular marker of dopaminoreceptive cells containing $D_{1}$ receptors (Ouimet et al., 1984). Dopamine is well represented and unevenly distributed in the amygdala (Brownstein et al., 1974; Ben-Ari et al., 1975) with a striking 75 -fold gradient in DA concentration between adjacent amygdaloid nuclei (Kilts and Anderson, 1986). This heterogeneous distribution of DA suggests that the functional significance of DA neurotransmission in the amygdala varies between its component nuclei.

The key functional event of neuronal DA synthesis appears 
to be under the regulatory influence of at least 4 mechanisms (Demarest et al., 1983). One of these mechanisms, nerve terminal DA autoreceptors, is inequivalently expressed in different DA systems, with a subset of mcsocortical (Bannon et al., 1981a, 1982) and hypothalamic (Demarest and Moore, 1979) DA neuronal populations postulated to be pharmacologically and functionally unique as a result of a lack of this modulatory mechanism. The present investigation sought to corroborate, by using complementary approaches, preliminary evidence suggesting a lack of synthesis-modulating autoreceptors localized on DA terminals innervating the majority of amygdaloid nuclei (Anderson et al., 1985). These comparisons were extended to other mesolimbic DA neuronal populations and mechanisms of synthesis regulation. Our findings indicate that terminal autoreceptors are operative in regulating the synthetic activity of only a minority of DA-innervated brain structures, while end-product inhibition is ubiquitously expressed, and that any conclusion as to the presence or absence of presynaptic DA synthesis-regulating autoreceptors is dependent on the chosen method or technique of study. These results suggest that a reorganization of the mesolimbic DA system into subsystems delineated by functional rather than exclusively anatomical endpoints is needed. Furthermore these findings furnish a possible physiological basis for the general nonsuccess of low-dose DA agonist administration in the treatment of schizophrenia.

\section{Materials and Methods}

These studies sought to determine the relative involvement of nerve terminal DA autoreceptors in the regulation of DA synthesis in neuronal populations projecting to discrete limbic nuclei. To this end, the biochemically estimated response of DA-containing nerve terminals under 3 conditions of isolation from the impulse-mediated influences of their cell bodies or feedback loops was determined, as follows: (1) the cessation of impulse-coupled release following the administration of gammabutyrolactone (GBL) (Walters and Roth, 1976), (2) surgical transection of ascending DA neurons (Kehr et al., 1977), and (3) the administration of a low, presumably autoreceptor-selective dose of the direct-acting DA agonist apomorphinc (Bannon et al., 1983).

General. Male Sprague-Dawley albino rats (Charles River, Wilmington, MA) weighing 210-245 gm, were housed in pairs in temperatureand humidity-controlled quarters maintained on a $12 \mathrm{hr}$ light/dark cycle with lights on at 0700 hours. The following drugs were used at the indicated administration-decapitation intervals: GBL (35 min; Sigma Chemical Co., St. Louis, MO), $m$-hydroxybenzylhydrazine HCl (NSD1015, 30 min; Sigma), apomorphine HCl (40 or $30 \mathrm{~min}$; Sigma), and pargyline $\mathrm{HCl}$ (45 min; Sigma). Drugs were administered as solutions in isotonic saline $(0.9 \% \mathrm{NaCl})$ by an intraperitoneal (GBL, NSD-1015, pargyline) or subcutaneous (apomorphine) route.

Medial forebrain bundle (MFB) knife cut transections. Thirty-three rats $(288.5 \pm 11.3 \mathrm{gm})$ were subjected to unilateral coronal MFB knife cuts under halothane (Fluothane; Ayerst Laboratories) anesthesia. MFB knife cuts were performed according to a modification of the procedures outlined by Paxinos and Bindra (1973). A retractable tungsten wire knife $(0.13 \mathrm{~mm}$ diameter) housed in a stainless steel guide cannula (26 gauge) was used. The guide cannula containing the retractable wire knife was positioned $3.18 \mathrm{~mm}$ anterior to lambda and $0.5 \mathrm{~mm}$ lateral to midline (superior sagittal sinus), according to the atlas of Konig and Klippel (1963). The guide cannula was lowered $5.0 \mathrm{~mm}$ below dura and the knife blade extended. When fully extruded, the arc-shaped knife blade extended another $2.0 \mathrm{~mm}$ vertically and $2.0 \mathrm{~mm}$ laterally from the tip of the guide cannula. The MFB transection was made by lowering the guide cannula to the base of the brain and subsequently returning it to the initial point of knife extension. The knife blade was then retracted and the knife assembly removed from the brain.

Eleven rats received NSD- $1015(100 \mathrm{mg} / \mathrm{kg}$, i.p.) $5 \mathrm{~min}$ after unilateral transection of the MFB, and were decapitated 30 min later. The extent of 3,4-dihydroxyphenylalanine (DOPA) accumulation in brain nuclei ipsilateral and contralateral to the side subjected to knife cuts was determined and compared. Seven rats were killed $35 \mathrm{~min}$ after MFB transection, and 8 others after $7 \mathrm{~d}$. The DA and norepinephrine (NE) contents of brain nuclei ipsilateral and contralateral to the side of transection were determined and compared. Seven rats ( 5 acute and 2 chronic preparations) were randomly selected for histological verification of MFB transection.

Following sectioning, $40-\mu \mathrm{m}$-thick coronal sections were stained by the technique of Kluver and Barrera (1953) prior to light microscope examination. In 5 (4 acute and 1 chronic preparation) of the 7 rats, MFB transection was verified, with the center of the transection ranging from 2.97 to $3.29 \mathrm{~mm}$ anterior to lambda (Konig and Klippel, 1963). The knife cuts could not be localized in the remaining 2 brains. The approximate anterior-posterior position of the knife damage in unfixed, unstained brains was assessed and recorded for all acute preparations during the generation of coronal sections for the micropunch dissection of brain nuclei or areas.

Microdissection of brain nuclei. Discrete brain nuclei (aggregations of neuronal cell bodies in the CNS) were micropunch-dissected from unfixed, frozen coronal brain sections (Palkovits, 1973; Palkovits and Brownstein, 1983). Subjects were killed by decapitation, and brains rapidly removed and frozen ventral side up on dry ice. Brains were mounted in a cryostat/microtome (Damon/IEC, Needham Heights, MA) and sliced into $300-\mu \mathrm{m}$-thick coronal sections at a chamber temperature of $-10^{\circ} \mathrm{C}$. Brain nuclei and areas were bilaterally micropunched from consecutive sections using thin-walled stainless steel tubing of $0.57,0.75$, 0.91 , or $1.15 \mathrm{~mm}$ I.D. (Small Parts, Miami, FL) with the aid of a stereomicroscope (Kilts and Anderson, 1986). The atlas of Konig and Klippel (1963) and the reports of Palkovits et al. (1974) and Jacobowitz and Palkovits (1974) served as general guides, the latter being particularly useful in the dissection of the more posterior amygdaloid nuclei. The approximate location and geometry of the component nuclei of the amygdala and septum and the subdivisions of the bed nucleus of the stria terminalis are schematically illustrated in Figure 1. Samples were blown into $500 \mu 1$ polypropylene microcentrifuge tubes, frozen on dry ice, and stored at $-80^{\circ} \mathrm{C}$ until assayed.

On-line trace enrichment high performance liquid chromatographyelectrochemical detection $(H P L C-E C)$ assays for $D A, N E, D O P A, 3,4$ dihydroxyphenylacetic acid (DOPAC), 3-methoxy,4-hydroxyphenylacetic acid (HVA) and 5-hydroxyindoleacetic acid (5-HIAA). These assays were specifically developed for the biochemical estimation of the functional activity of DA, NE, and 5-HT-containing neurons in the CNS at the level of discrete hrain nuclei. Each assay uses distinct physicochemical properties of each neurochemical of interest to effect their on-line enrichment by ion-exchange HPLC and counter-ion-dependent back-elution and subsequent separation by reverse-phase, ion-pair HPLC, followed by electrochemical detection. Assay sensitivity, primarily a byproduct of the specificity imparted by complementary functional groupselective HPLC retention and detection mechanisms, was sufficient to permit the quantification of as little as $25 \mathrm{pg}$ of each neurochemical of interest per sample. The potential benefits, complementary nature of each component, and configuration and illustration of these on-line trace-enrichment HPLC-EC assays have been described in detail elsewhere (Koch and Kissinger, 1980; Kilts and Bero, 1984; Kilts et al., 1984a).

Tissue samples were assayed for DA and NE content by an on-line trace enrichment HPLC-EC assay, described in detail elsewhere (Kilts and Anderson, 1986) and modified for DOPA determinations. Samples were homogenized by ultrasonic cell disruption in $300 \mu \mathrm{l}$ of $0.2 \mathrm{M} \mathrm{HClO}_{4}$ containing $0.5 \mathrm{~mm}$ sodium metabisulfite, $0.5 \mathrm{~mm}$ EDTA, and either 0.96 or $2 \mathrm{ng}$ of 3,4-dihydroxybenzylamine (DHBA) or $1.2,2.4$, or $6 \mathrm{ng}$ of $\alpha$-methyl-3,4-dihydroxyphenylalanine ( $\alpha$-methyl DOPA) as internal standards. 3,4-Dihydroxylated catechols in the supernatants, resulting from homogenate centrifugation $\left(10,000 \times g\right.$ for $5 \mathrm{~min}$ at $\left.4^{\circ} \mathrm{C}\right)$, were off-line alumina-extracted, on-line enriched on a short cation exchange HPLC enrichment column, efficiently back-eluted as a function of increased counter-ion (potassium) concentration in the analytical/elution mobile phase, separated by reverse phase, ion-pair HPLC, and amperometrically detected following their electrochemical oxidation at a working electrode potential of $+600 \mathrm{mV}$ versus a $\mathrm{Ag} / \mathrm{AgCl}$ reference electrode. Enrichment mobile phases consisted of $0.02 \mathrm{M}$ citrate, $0.02 \mathrm{M}$ potassium acetate, $0.5 \mathrm{mM}$ EDTA (final $\mathrm{pH}$ of 3.5 ), and $0.5-2.5 \%$ (vol/ vol) acetonitrile for DA and NE determinations, and of $0.02 \mathrm{M}$ monobasic potassium phosphate, $0.5 \mathrm{~mm}$ EDTA (adjusted $\mathrm{pH}, 2.75$ ), and $0.5-2.5 \%$ acetonitrile for DOPA determinations. Analytical/elution mobile phases consisted of $0.02 \mathrm{M}$ citrate, $0.2 \mathrm{M}$ potassium acetate, $0.5 \mathrm{mM}$ EDTA, 0.5-1.0 mm sodium octanesulfonate ( $\mathrm{pH} 5.3$ ), and $2-4 \%$ ace- 

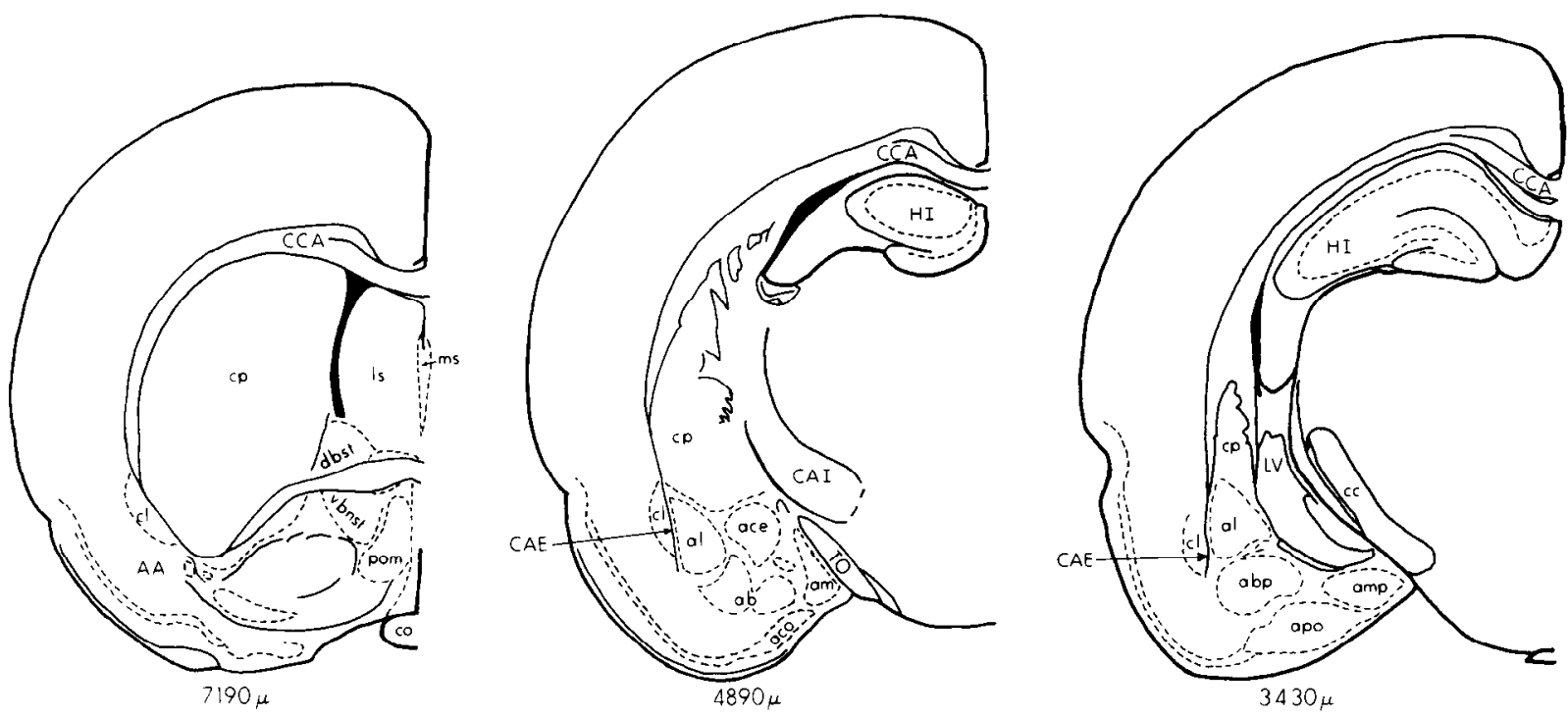

Figure 1. Schematic illustration of the approximate location and geometry of the component nuclei of the amygdala and septum and the subdivisons of the interstitial (bed) nucleus of the stria terminalis. Drawings represent frontal sections of the rat brain at different indicated levels anterior to the interaural line (frontal zero plane), as modified from the atlas of Konig and Klippel (1963). Abbreviations correspond to the following brain structures: $A A$, anterior amygdaloid area; $a c e$, central amygdaloid nucleus; $a l$, lateral amygdaloid nucleus; $a b$, basal amygdaloid nucleus; $a m$, media amygdaloid nucleus; $a c o$, cortical amygdaloid nucleus; $a p o$, posterior amygdaloid nucleus; $a m p$, medial posterior amygdaloid nucleus; $a b p$, basal posterior amygdaloid nucleus; $d b s t$, dorsal bed nucleus stria terminalis; $v b n s t$, ventral bed nucleus stria terminalis: $C A$, anterior commissure; $C A E$, external capsule; $C A I$, in ternal capsule; $c c$, crus cerebri; $C C A$, corpus callosum; $c l$, claustrum; $c o$, optic chiasm; $c p$, caudate putamen; $H I$, hippocampus; $l s$, lateral septal nucleus; $L V$, lateral ventricle; $m s$, medial septal nucleus; pom, medial preoptic nucleus; $T O$, optic tract.

tonitrile for DA and NE determinations, and of $0.2 \mathrm{M}$ monobasic potassium phosphate, 0.5 mм EDTA, $0.5-1.5 \mathrm{~mm}$ sodium octanesulfonate (adjusted pH of 2.75), and 3-5\% acetonitrile for DOPA determinations. The relatively low pH of the mobile phase used for the on-line trace enrichment assay of DOPA effectively suppresses the ionization of the carboxylate group of this amino acid (Kilts et al., 1981) and thus permits the unhindered cation exchange enrichment, back-elution, and ion-pair, reverse phase separation of DOPA as protonated amines.

Both DA and NE can also be quantified by the assay system optimized for DOPA determinations, though with less sensitivity, precision, and accuracy than that obtained with the assay specially designed for their quantification

The unknown concentrations of DA and NE or of DOPA in micropunched tissue samples were determined using blank-corrected calibration curves generated by assaying a series of standard solutions $(0.2 \mathrm{M}$ $\mathrm{HClO}_{4}, 0.5$ m $\mathrm{mDTA}, 0.5 \mathrm{~mm}$ sodium metabisulfite) containing varying amounts $(0,25-5000 \mathrm{pg})$ of DA and NE or DOPA and a constant amount of DHBA or $\alpha$-methyl DOPA. The ratios of the detector response (peak height) for NE, DA, or DOPA, relative to that of the internal standard, were calculated, and catechol concentrations in tissue samples were determined using the slope and intercept of the appropriate calibration curve.

For the on-line trace enrichment HPLC-EC determination of the DOPAC, HVA, and 5-HIAA content of discrete brain nuclei, samples were homogenized by ultrasonic cell disruption in $275 \mu \mathrm{l}$ of $0.1 \mathrm{M}$ acetic acid: methanol $(1: 1)$, and a $50 \mu \mathrm{l}$ aliquot of the homogenate was removed for protein determination. Following centrifugation $(10,000 \times$ $g$ for $15 \mathrm{~min}$ at $4^{\circ} \mathrm{C}$ ), a $200 \mu \mathrm{l}$ aliquot of the supernatant was removed and mixed with $250 \mu \mathrm{l}$ of deionized water, and the entire sample was injected into the HPLC. DOPAC, HVA, and 5-HIAA were on-line enriched as carboxylate anions on a short anion exchange (Spherisorb S5 SAX resin; Phase-Sep, Hauppauge, NY) HPLC enrichment column, efficiently back-eluted as a function of an increased counter-ion (acetate) concentration in the elution/analytical mobile phase, separated by reverse phase HPLC, and amperometrically detected following their electrochemical oxidation at a working electrode potential of $+750 \mathrm{mV}$ versus a $\mathrm{Ag} / \mathrm{AgCl}$ reference electrode. The enrichment mobile phase consisted of $0.05 \mathrm{~m}$ acetic acid (adjusted $\mathrm{pH}$ of 3.5 ) and $5 \%$ acetonitrile. The elution/analytical mobile phase consisted of $0.2 \mathrm{M}$ acetic acid, 0.5 mM EDTA (adjusted pH of 3.5), and $7.5 \%$ acetonitrile. Samples were enriched over a 2 min period following their injection into the HPLC and then back-eluted ( $1 \mathrm{~min}$ ) onto the analytical column using isocratic mobile phase flow rates of $1.25 \mathrm{ml} / \mathrm{min}$.

Calibration curves were generated by assaying a series of standard solutions $[0.1 \mathrm{M}$ acetic acid : methanol (1:1)] containing varying amounts $(0,50-5000 \mathrm{pg})$ of DOPAC, HVA, and 5-HIAA. The unknown concentration of these monoamine metabolites in micropunched tissue samples was calculated from their respective chromatographic peak heights using the slope and intercept of the appropriate calibration curve.

Data analysis. Significant differences between experimental group means were analyzed using Student's $t$ test or a one-way analysis of variance, followed by pairwise comparisons by the Newman-Keul's procedure $(\alpha=0.05)$.

\section{Results}

Relative effects of $G B L$ and $M F B$ transection on the $D A$ concentration of discrete brain nuclei

The administration of GBL is typically associated with a profound increase in the concentration of DA in diverse brain regions (Pericic and Walters, 1976; Demarest and Moore, 1979), presumably because of continued or enhanced DA synthesis accompanied by a drug-induced inhibition of DA release (Bannon et al., 1981a). While reflecting the net influences of a multitude of presynaptic functions, a GBL-induced increase in DA concentration is often considered to be indicative of the presence of tonically active, synthesis-modulating DA nerve terminal autoreceptors and to represent a neurochemical baseline by which relative autoreceptor sensitivity can be assessed as a function of the dose-related antagonism by DA receptor agonists. A comparison of the relative efficacy of GBL $(750 \mathrm{mg} / \mathrm{kg})$ to increase the DA concentration of amygdaloid and other limbic nuclei indicated a response of lesser magnitude than that observed in the caudate nucleus, nucleus accumbens, olfactory tubercle, and cerebrocortical areas (Roth, 1984; Table 1). The disparity in response between mesoamygdaloid and these latter DA neuronal populations was apparent either 30 or $60 \mathrm{~min}$ following 
Table 1. Effect of gammabutyrolactone (GBL) administration on the dopamine (DA) content of discrete brain nuclei or areas

\begin{tabular}{|c|c|c|c|}
\hline \multirow[b]{2}{*}{ Brain nuclei or area } & \multicolumn{3}{|c|}{ DA concentration ( $\mathrm{ng} / \mathrm{mg}$ protein) } \\
\hline & 0 min after GBL & 30 min after GBL & 60 min after GBL \\
\hline \multicolumn{4}{|l|}{ Amygdaloid } \\
\hline Central & $28.8 \pm 2.0$ & $35.3 \pm 0.85(22.5)$ & $41.5 \pm 4.6$ \\
\hline Lateral & $10.8 \pm 0.84$ & $11.4+2.2(5.5)$ & $15.6 \pm 1.6 \quad(44.4)$ \\
\hline Basal & $4.8 \pm 0.36$ & $8.0 \pm 0.72(67.5)$ & $7.0 \pm 0.48(45)$ \\
\hline Medial & $0.4 \pm 0.07$ & n.a. & $0.95 \pm 0.20(139.4)$ \\
\hline Cortical & $1.6 \pm 0.36$ & $2.2 \pm 0.35(38.5)$ & $1.8 \pm 0.11(15.4)$ \\
\hline Posterior & $1.1 \pm 0.08$ & $1.7 \pm 0.02(59.1)$ & $1.2 \pm 0.08(13.6)$ \\
\hline Medial posterior & $0.65 \pm 0.1$ & $0.91 \pm 0.06(40.7)$ & $0.83 \pm 0.10(27.8)$ \\
\hline \multicolumn{4}{|c|}{$\begin{array}{l}\text { Interstitial (bed) nucleus } \\
\text { of stria terminalis }\end{array}$} \\
\hline Dorsal & $33.7 \pm 2.6$ & $50.2 \pm 6.8 \quad(48.8)$ & n.a. \\
\hline Ventral & $17.6 \pm 0.96$ & $25.2 \pm 3.1 \quad(42.9)$ & $19.2 \pm 1.4$ \\
\hline \multicolumn{4}{|l|}{ Hypothalamic } \\
\hline Paraventricular & $8.9 \pm 0.24$ & $11.0 \pm 1.2$ & $11.4 \pm 1.1$ \\
\hline Dorsomedial & $3.2 \pm 0.24$ & $5.0 \pm 0.31(55.6)$ & $4.8 \pm 0.4$ \\
\hline Ventromedial & $2.0 \pm 0.12$ & $2.4 \pm 0.19(17.6)$ & $2.5 \pm 0.29(23.5)$ \\
\hline Anterior & $1.9 \pm 0.08$ & $2.9 \pm 0.41(50.0)$ & $2.5 \pm 0.16(31.3)$ \\
\hline Medial preoptic & $4.2 \pm 0.84$ & $4.6 \pm 0.50(8.6)$ & $5.4 \pm 0.38(28.6)$ \\
\hline \multicolumn{4}{|l|}{ Cerebrocortical } \\
\hline Medial prefrontal & $0.37 \pm 0.02$ & $0.73 \pm 0.04(96.8)$ & $0.74 \pm 0.06(100)$ \\
\hline Cingulate & $0.2 \pm 0.01$ & $0.92 \pm 0.17(352.9)$ & $0.97 \pm 0.22(376.5)$ \\
\hline Entorhinal & $1.2 \pm 0.10$ & $2.0 \pm 0.07(77.1)$ & $2.2 \pm 0.19(87.5)$ \\
\hline Caudate nucleus & $77.4 \pm 9.5$ & $162.2 \pm 21.2(109.6)$ & $198.4 \pm 20.3(156.3)$ \\
\hline Olfactory tubercle & $34.9 \pm 4.2$ & $115.4 \pm 17.8(230.6)$ & $113.3 \pm 9.1 \quad(224.4)$ \\
\hline
\end{tabular}

Animals were killed either 30 or $60 \mathrm{~min}$ following the administration of GBL $(750 \mathrm{mg} / \mathrm{kg}$, i.p.). Values represent means \pm SEM of 3-6 determinations. Numbers in parentheses represent the percentage increase in DA concentration compared to that in untreated ( 0 time) control subjects.

n.a., Not assayed.

GBL administration. A possible explanation for this disparity is that a significantly greater fraction of the DA content of the amygdaloid nuclei represents DA as a synthetic precursor in NE neurons, the latter being relatively unaffected by GBL administration (Roth et al., 1973; Nowycky and Roth, 1978). Indeed, the administration of GBL did not significantly affect the concentration of NE in any of the brain nuclei or areas examined as compared to vehicle-injected controls (data not shown). However, the relatively small effect of GBL on amygdaloid nuclei DA concentration was also inconsistently reduced by the administration of apomorphine $(1 \mathrm{mg} / \mathrm{kg}$, i.p.).

Acute unilateral transection of the MFB produced a profile of effects on the concentration of DA in distinct projection fields that was qualitatively similar, though of lesser magnitude, than that produced by GBL administration (Fig. $2 A$ ). Consistent with previous reports (Walters et al., 1973), the DA concentration in the anterior dorsolateral and ventromedial caudate nucleus and in the olfactory tubercle was significantly increased ipsilateral to the side of transection as compared to that in the unoperated, contralateral side. By contrast, the DA content of the majority of the amygdaloid nuclei, subdivisions of the bed nucleus of the stria terminalis, lateral septum, and medial prefrontal and cingulate cortex was unaltered by acute axotomy. Of the limbic nuclei examined, only the cortical amygdaloid nucleus and anterior amygdaloid area exhibited axotomy-induced increases in DA concentration. In none of the brain nuclei or areas examined was the concentration of NE altered by acute axotomy. The significant decrease in DA as well as NE content in the majority of brain nuclei or areas noted $5 \mathrm{~d}$ following unilateral MFB transection (Fig. $2 B$ ) attests to the correct placement of the knife cuts.

The results of these initial experiments indicated that DA concentration represented an unsuitable index of the response to a cessation of impulse flow in mesoamygdaloid and other limbic DA neurons by which the relative role of synthesis-modulating terminal autoreceptors can be assessed.

Effects of $G B L$ alone or in combination with apomorphine on NSD-1015-induced DOPA accumulation in discrete brain nuclei

These experiments used a pharmacological/biochemical approach (Carlsson et al., 1972) to determine the rate of in vivo tyrosine hydroxylation. In the majority of amygdaloid and other subcortical limbic nuclei, DOPA accumulation predominantly reflects synthesis in $\mathrm{DA}$, rather than $\mathrm{NE}$, neurons, as inferred from the differential rates of DA and NE synthesis estimated from an examination of the relative rates of their depletion by $\alpha$-methyltyrosine (Kilts and Anderson, 1987). In the NE-rich medial amygdaloid nucleus, ventral subdivision of the bed nucleus of the stria terminalis, and hippocampal subfields, the NSD-1015-induced accumulation of DOPA probably reflects synthesis of both DA and NE. The inhibition of L-aromatic 

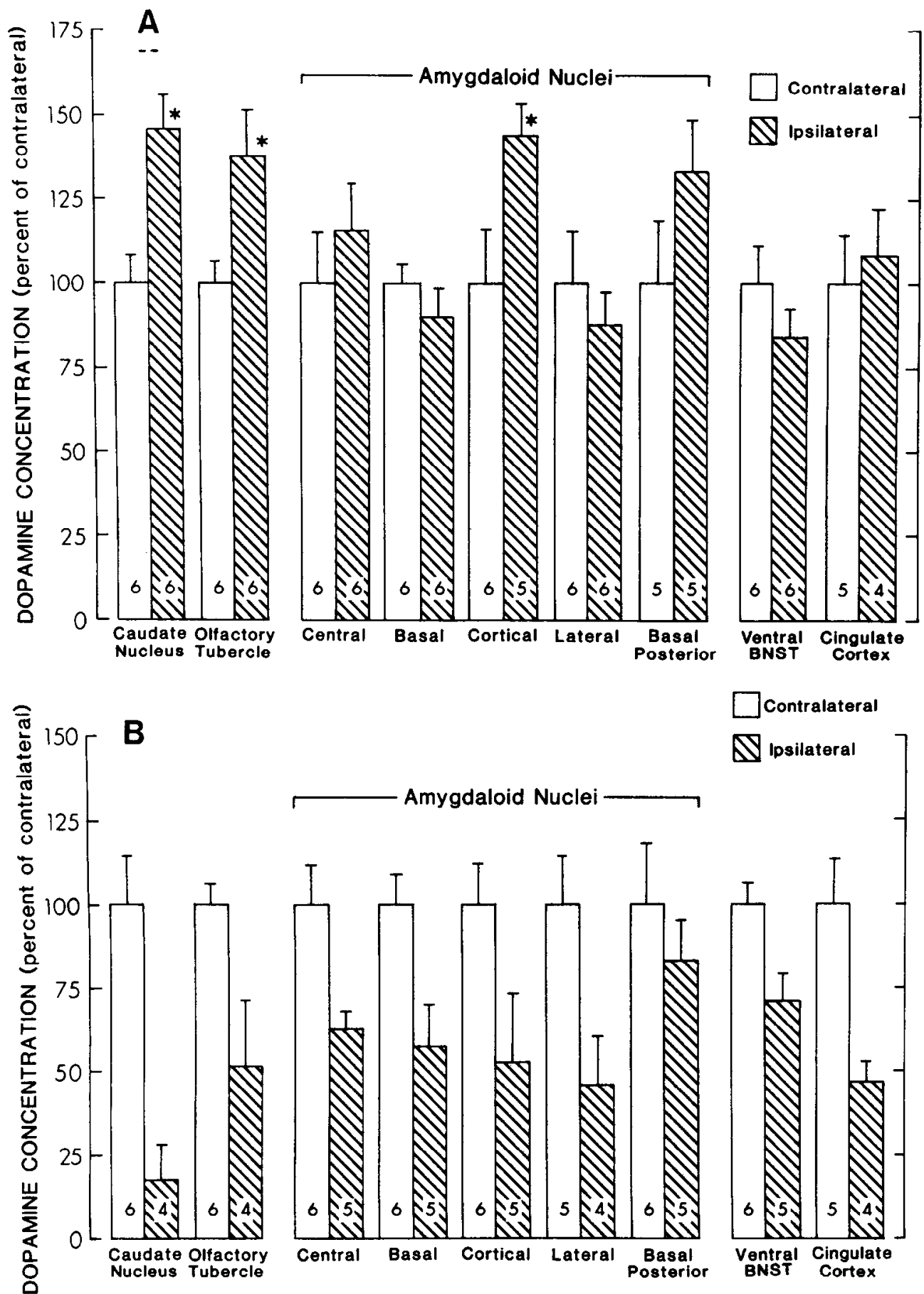

Figure 2. A, Acute effects of transection of the medial forebrain bundle (MFB) on the concentration of DA in discrete rat brain nuclei or areas. Unilateral transections were performed under halothane anesthesia using stereotaxically guided wire knives, and animals were killed $35 \mathrm{~min}$ later. The DA concentration of discrete projection fields ipsilateral to the side of transection is expressed as a percentage $( \pm 1$ SEM) of the corresponding contralateral value. Numbers at the base of each histobar represent the number of determinations per group. ${ }^{*} p<0.05$ relative to contralateral values. $B$, Longterm effects of transection of the MFB on the concentration of DA in discrete rat brain nuclei or areas. Unilateral transections were performed under halothane anesthesia using stereotaxically guided wire knives, and animals were killed $5 \mathrm{~d}$ later. See $A$ for details of data presentation.

amino acid decarboxylase by NSD-1015 produced a profound accumulation of DOPA in all brain nuclei or areas examined 30 min following drug administration (Table 2).

The distribution of tonically inhibitory, synthesis-modulating DA autoreceptors on terminals of distinct DA neuronal populations projecting to discrete limbic and nonlimbic nuclei is summarized in Tables 2 and 3. An increased DA synthesis resulting from a GBL-induced decrease in both synaptic DA content and the consequent autoreceptor occupancy represented the predetermined criterion defining their functional presence. The ability of apomorphine ( $1 \mathrm{mg} / \mathrm{kg}$ ) to block the effect of GBL was examined, though not considered to represent a definitive criterion because of the confounding influence of non-receptormediated drug actions and effects mediated by actions on autoreceptor populations regulating presynaptic functions other than DA synthesis.

Consistent with previous reports (Nowycky and Roth, 1978; Anden et al., 1983; Demarest et al., 1983), the cessation of neuronal impulse flow and coupled DA release evoked by GBL administration results in a 2-4-fold increase in the rate of DOPA accumulation in the dorsolateral and ventromedial caudate nucleus, nucleus accumbens, and olfactory tubercle. Apomorphine administration blocked the GBL-induced increase in DOPA accumulation in all of these DA neuronal projection fields. The 


\begin{tabular}{|c|c|c|c|}
\hline \multirow[b]{2}{*}{ Brain nuclei or area } & \multicolumn{3}{|c|}{ DOPA concentration (ng/mg protein) } \\
\hline & Vehicle-treated & GBL-treated & $\begin{array}{l}\text { Apomorphine/ } \\
\text { GBL-treated }\end{array}$ \\
\hline \multicolumn{4}{|l|}{ Cerebral cortex } \\
\hline Medial prefrontal & $1.7 \pm 0.26$ & $1.6 \pm 0.10$ & $1.4 \pm 0.19$ \\
\hline Cingulate & $1.4 \pm 0.03$ & $2.4 \pm 0.19^{*}$ & $1.3 \pm 0.11^{* *}$ \\
\hline Entorhinal & $3.5 \pm 0.17$ & $3.0 \pm 0.10$ & $2.6 \pm 0.14$ \\
\hline Pyriform & $1.8 \pm 0.05$ & $1.7 \pm 0.19$ & $1.3 \pm 0.06^{* *}$ \\
\hline \multicolumn{4}{|l|}{ Basal ganglia } \\
\hline Dorsomedial caudate nucleus & $18.4 \pm 0.98$ & $58.4 \pm 3.2^{*}$ & $11.6 \pm 0.79^{* *}$ \\
\hline Ventromedial caudate nucleus & $18.5 \pm 2.6$ & $85.8 \pm 6.8^{*}$ & $13.8 \pm 2.0^{* *}$ \\
\hline Posterior caudate-putamen & $9.4 \pm 0.56$ & $17.4 \pm 1.9^{*}$ & $7.1 \pm 1.3^{* *}$ \\
\hline \multicolumn{4}{|l|}{ Ventromedial mesencephalon } \\
\hline \multicolumn{4}{|l|}{ Substantia nigra } \\
\hline pars compacta & $25.1 \pm 1.9$ & $33.4 \pm 1.2^{*}$ & $20.3 \pm 2.8^{* *}$ \\
\hline pars reticulata & $10.0 \pm 0.74$ & $8.6 \pm 0.84$ & $6.0 \pm 0.66^{* *}$ \\
\hline pars lateralis & $4.2 \pm 0.46$ & $3.5 \pm 0.20$ & $2.9 \pm 0.25$ \\
\hline \multicolumn{4}{|l|}{ Ventral tegmental area } \\
\hline medial & $17.0 \pm 2.5$ & $11.5 \pm 1.6$ & $6.6 \pm 0.56^{* *}$ \\
\hline lateral & $23.3 \pm 1.2$ & $17.0 \pm 1.1^{*}$ & $12.7 \pm 1.4$ \\
\hline
\end{tabular}

Apomorphine (1 mg/kg, s.c.) and/or GBL ( $750 \mathrm{mg} / \mathrm{kg}, \mathrm{i} . \mathrm{p}$.) were administered 45 and $35 \mathrm{~min}$ before animals were killed, respectively; NSD-1015 (100 mg/kg, i.p.) was administered $30 \mathrm{~min}$ before animals were killed. Values represent the means \pm SEM of 4-7 determinations.

* Significantly different $(p<0.05)$ from vehicle-treated animals.

** Significantly different $(p<0.05)$ from GBL-treated animals

inhibitory influence of apomorphine was of lesser magnitude in the neostriatal areas than in the nucleus accumbens and olfactory tubercle, perhaps reflecting the putative differential sensitivity of synthesis-regulating DA autoreceptors on terminals of these distinct DA neuronal populations (Nowycky and Roth, 1978; Demarest et al., 1983; Westfall et al., 1983). Moreover, apomorphine $(0.03$ and $0.3 \mathrm{mg} / \mathrm{kg})$ antagonized the GBL-induced increase in DOPA accumulation in these brain nuclei with a greater potency and efficacy than the GBL-induced increases in DA concentration (data not shown), thereby reinforcing the inequivalency of these 2 indices of DA neuronal response to GBL.

Populations of mesocortical DA neurons have been delineated on the basis of the absence or presence of DA synthesisregulating terminal autoreceptors (Bannon et al., $1981 \mathrm{a}$; Chiodo et al., 1984). The administration of GBL did not alter the rate of DOPA accumulation in the medial prefrontal, entorhinal, or piriform cortex. Similar findings have been reported previously for the medial prefrontal cortex by Bannon et al. (1981a). In contrast, the rate of DOPA accumulation in the cingulate cortex was significantly increased following GBL administration, and was blocked by apomorphine. These results suggest that alterations in the synaptic content of DA differentially influence DA synthesis in populations of mesocortical DA neurons, presumably as a function of a differential neuronal population distribution of synthesis-modulating autoreceptors. Consistent with the reported absence of synthesis-modulating DA autoreceptors on terminals of the tuberoinfundibular DA system (Demarest and Moore, 1979), the rate of DOPA accumulation in the median eminence was not altered by GBL. The results of the present study, obtained using brain nuclei that were micropunch-dissected from frozen coronal brain slices, in large part corroborate the collective literature reports concerning the distribution of synthesis-regulating nerve terminal autoreceptors in the nucleus accumbens, caudate nucleus, olfactory tubercle, medial prefrontal cortex, and median eminence.

The present study examined the effects of GBL in the 8 major dissectable nuclei of the amygdala and in the anterior amygdaloid area, an amygdaloid-associated area consisting primarily of fibers in passage. Without exception, the accumulation of DOPA in the amygdaloid nuclei was not increased by GBL and, in fact, was significantly decreased in the central and basal amygdaloid nuclei. Pretreatment with apomorphine either decreased or did not affect the rate of DOPA accumulation in the amygdaloid nuclei relative to animals receiving only GBL. Since the estimated rate of DA synthesis in the component nuclei of the amygdaloid complex is not increased by a diminished synaptic DA content, it would appear that the populations of DA neurons innervating discrete amygdaloid nuclei lack tonically inhibitory terminal autoreceptors regulating neuronal DA synthesis. It was of further interest to examine whether this regulatory feature was unique to the component nuclei of the amygdala or generalized to other limbic structures. The accumulation of DOPA in the lateral and medial septal nuclei, dorsal hippocampus (predominantly CA1 and CA4 subfields), and dorsal and ventral subdivisions of the bed nucleus of the stria terminalis was not increased by GBL administration. Values in the subdivisions of the bed nucleus of the stria terminalis were significantly decreased compared to those in vehicle-injected controls. Apomorphine pretreatment significantly decreased DOPA accumulation relative to subjects receiving GBL alone in all of these extra-amygdaloid limbic nuclei.

Using the GBL-DOPA accumulation model, subsequent experiments sought to map the distribution of somatodendritic or 
Table 3. Effect of GBL administration alone or in animals pretreated with apomorphine on the rate of DOPA accumulation in discrete limbic brain nuclei or areas

\begin{tabular}{|c|c|c|c|}
\hline \multirow[b]{2}{*}{ Brain nuclei or area } & \multicolumn{3}{|c|}{ DOPA concentration (ng/mg protcin) } \\
\hline & Vehicle-treated & GBL-treated & $\begin{array}{l}\text { Apomorphine/ } \\
\text { GBL-treated }\end{array}$ \\
\hline \multicolumn{4}{|l|}{ Amygdaloid } \\
\hline Central & $6.6+0.36$ & $4.9 \pm 0.13^{*}$ & $2.5 \pm 0.18^{* *}$ \\
\hline Lateral & $5.9 \pm 0.25$ & $5.5 \pm 0.49$ & $2.4 \pm 0.19^{* *}$ \\
\hline Basal & $3.7 \pm 0.18$ & $2.4 \pm 0.26^{*}$ & $1.8 \pm 0.11$ \\
\hline Medial & $2.6 \pm 0.20$ & $3.5 \pm 0.52$ & $2.6 \pm 0.43$ \\
\hline Cortical & $2.5 \pm 0.30$ & $2.2 \pm 0.28$ & $1.6 \pm 0.23$ \\
\hline Posterior & $1.9 \pm 0.07$ & $1.9 \pm 0.20$ & $1.4 \pm 0.19$ \\
\hline Medial posterior & $1.1 \pm 0.04$ & $1.3 \pm 0.14$ & $1.0 \pm 0.11$ \\
\hline Basal posterior & $3.1 \pm 0.25$ & $2.5 \pm 0.41$ & $1.9 \pm 0.29$ \\
\hline Anterior amygdaloid area & $3.7 \pm 0.28$ & $3.1 \pm 0.19$ & $1.6 \pm 0.23^{* *}$ \\
\hline \multicolumn{4}{|l|}{ Septal } \\
\hline Lateral & $6.1 \pm 0.46$ & $5.2 \pm 0.95$ & $2.3 \pm 0.16^{* *}$ \\
\hline Medial & $3.0 \pm 0.31$ & $3.4 \pm 0.26$ & $2.3 \pm 0.29$ \\
\hline \multicolumn{4}{|c|}{ Interstitial (bed) nucleus of stria terminalis } \\
\hline Dorsal & $6.6 \pm 0.61$ & $5.9 \pm 0.47$ & $3.5 \pm 0.40^{* *}$ \\
\hline Ventral & $13.0 \pm 1.0$ & $11.2 \pm 0.52$ & $9.1 \pm 0.41^{* *}$ \\
\hline \multicolumn{4}{|l|}{ Hippocampus } \\
\hline Dorsal & $0.78 \pm 0.08$ & $0.91 \pm 0.06$ & $0.80 \pm 0.10$ \\
\hline Ventral & n.a. & n.a. & n.a. \\
\hline \multicolumn{4}{|l|}{ Hypothalamus } \\
\hline Paraventricular & $5.9 \pm 0.24$ & $6.0 \pm 0.44$ & $4.2 \pm 0.22^{* *}$ \\
\hline Median eminence & $9.1 \pm 1.4$ & $8.2 \pm 1.2$ & $5.0 \pm 0.42^{* *}$ \\
\hline Nucleus accumbens & $19.8 \pm 2.9$ & $43.6 \pm 3.0^{*}$ & $8.4 \pm 0.67^{* *}$ \\
\hline Olfactory tubercle & $16.3 \pm 0.88$ & $37.2 \pm 4.2^{*}$ & $9.8 \pm 1.7^{* *}$ \\
\hline
\end{tabular}

See legend to Table 2 for details of dosing regimens.

n.a., Not assayed.

* Significantly different $(p<0.05)$ from vehicle-treated animals.

** Significantly different $(p<0.05)$ from GBL-treated animals.

nerve terminal autoreceptors regulating DA synthesis in the major DA cell body groups of the ventromedial mesencephalon (Dahlstrom and Fuxe, 1964; Swanson, 1982). On the basis of their retained response to DA receptor agonists and antagonists, DA neurons in the deafferented substantia nigra have been reported to possess synthesis-modulating autoreceptors (Argiolas et al., 1982). In the present study, the administration of GBL produced a significant increase in DOPA accumulation in the DA cell body-rich substantia nigra-pars compacta, but not in the substantia nigra-pars lateralis or substantia nigra-pars reticulata, the latter of which contains the dendritic processes of the pars compacta DA cell bodies (Björklund and Lindvall, 1975). These results suggest that the influence of locally released DA on DA synthesis in the substantia nigra (Argiolas et al., 1982) is mediated by autoreceptors localized on DA perikarya or terminals of axon collaterals rather than on dendrites. The synthesis of DA in the lateral and medial ventral tegmental area (VTA), which primarily consists of the nucleus paranigralis and nucleus parabrachialis pigmentosus (lateral VTA) and the nucleus interfascicularis and caudal linear nucleus (medial VTA), and which contains the cell bodies of origin of the mesolimbic and mesocortical DA systems, does not appear to be under the inhibitory influence of DA autoreceptors, as GBL administration decreased rather than increased the rate of DOPA accumulation.
Effects of surgical transection of the MFB on NSD-1015induced DOPA accumulation in discrete brain nuclei

The validity of our report of the differential distribution of synthesis-modulating DA autoreceptors, or of any study of similar intent using GBL as a pharmacological tool, is contingent upon the ability of GBL to equally efficaciously inhibit impulse activity in all DA neuronal populations studied, something that has not been electrophysiologically demonstrated. An alternative nonpharmacological approach to testing this possibility involves assessing the effects on nerve terminal DA synthesis of an inhibition of axonal impulse conduction subsequent to surgical transection of the ascending DA pathways that originate in the ventromedial mesencephalon (Kehr et al., 1977; Bannon et al., 1982). Like GBL, the rate of DOPA accumulation in the nucleus accumbens, dorsolateral and ventromedial caudate nucleus, olfactory tubercle, and cingulate cortex was significantly increased $35 \mathrm{~min}$ following acute transection of the MFB (Table 4). In contrast, transection of the MFB did not significantly alter DOPA accumulation in any of the 8 amygdaloid nuclei or the anterior amygdaloid area. Axotomy of the MFB also did not increase DOPA accumulation in the lateral scptal nuclcus or in either subdivision of the bed nucleus of the stria terminalis. The rate of DOPA accumulation in the ventral subfield of the hippocampus, however, was significantly increased following acute 


\begin{tabular}{|c|c|c|}
\hline \multirow[b]{2}{*}{ Brain nuclei or area } & \multicolumn{2}{|c|}{ DOPA concentration ( $\mathrm{ng} / \mathrm{mg}$ protein) } \\
\hline & Contralateral to lesion & Ipsilateral to lesion \\
\hline \multicolumn{3}{|l|}{ Amygdaloid } \\
\hline Central & $4.4 \pm 0.32(8)$ & $4.2 \pm 0.41(6)$ \\
\hline Lateral & $3.5 \pm 0.22(7)$ & $4.1 \pm 0.65(8)$ \\
\hline Basal & $2.5 \pm 0.12(8)$ & $2.2 \pm 0.17(8)$ \\
\hline Medial & $2.2 \pm 0.24(8)$ & $1.7 \pm 0.19(8)$ \\
\hline Cortical & $2.2 \pm 0.19(9)$ & $1.8 \pm 0.19(9)$ \\
\hline Posterior & $1.4 \pm 0.17(7)$ & $1.6 \pm 0.20(8)$ \\
\hline Medial posterior & $1.4 \pm 0.17(8)$ & $1.2 \pm 0.13(9)$ \\
\hline Basal posterior & $1.9 \pm 0.24(7)$ & $2.3 \pm 0.13(8)$ \\
\hline Anterior amygdaloid area & $2.2 \pm 0.13(9)$ & $2.4 \pm 0.18(9)$ \\
\hline \multicolumn{3}{|c|}{ Interstitial (bed) nucleus of stria terminalis } \\
\hline Dorsal & $7.6 \pm 0.61(7)$ & $6.2 \pm 0.46(7)$ \\
\hline Ventral & $8.2 \pm 0.80(8)$ & $6.4 \pm 0.24(9)$ \\
\hline \multicolumn{3}{|l|}{ Septal } \\
\hline Lateral & $3.4 \pm 0.14(8)$ & $3.7 \pm 0.49(8)$ \\
\hline \multicolumn{3}{|l|}{ Hippocampal } \\
\hline Dorsal & $0.56 \pm 0.07(9)$ & $0.84 \pm 0.14(9)$ \\
\hline Ventral & $1.2 \pm 0.07(9)$ & $1.6 \pm 0.07(9)^{*}$ \\
\hline \multicolumn{3}{|l|}{ Neostriatum } \\
\hline Dorsal caudate nucleus & $14.5 \pm 0.91(9)$ & $40.2 \pm 3.6(9)^{*}$ \\
\hline Ventromedial caudate nucleus & $17.2 \pm 1.7$ & $36.7 \pm 4.2(9)^{*}$ \\
\hline Posterior caudate-putamen & $7.4 \pm 0.22(8)$ & $10.3 \pm 1.0(8)^{*}$ \\
\hline Nucleus accumbens & $27.4 \pm 1.6$ & $37.3 \pm 5.5(8)^{*}$ \\
\hline Olfactory tubercle & $22.0 \pm 0.59(9)$ & $29.2 \pm 2.8(8)^{*}$ \\
\hline \multicolumn{3}{|l|}{ Cerebrocortical areas } \\
\hline Medial prefrontal & $0.96 \pm 0.07(8)$ & $1.1 \pm 0.04(8)$ \\
\hline Cingulate & $1.0 \pm 0.05(9)$ & $1.3 \pm 0.11(9)^{*}$ \\
\hline Pyriform & $1.6 \pm 0.12(8)$ & $1.8 \pm 0.13(6)$ \\
\hline Entorhinal & $1.8 \pm 0.11(8)$ & $1.8 \pm 0.06(8)$ \\
\hline
\end{tabular}

Unilateral transections were performed under halothane anesthesia using stereotaxically guided wire knives. Animals were administered NSD-1015 (100 mg/kg, i.p.) $5 \mathrm{~min}$ following axotomy and were killed $30 \mathrm{~min}$ later. Numbers in parentheses represent the number of determinations per group.

* Significantly different $(p<0.05)$ from contralateral values.

transection of the MFB. A comparison of the effects of GBL administration and MFB transection on estimated rates of DA synthesis in discrete neuronal projection fields indicates striking parallels that reinforce the postulated absence of DA synthesismodulating autoreceptors on DA nerve terminals that innervate subcortical limbic brain structures, and corroborates the effectiveness of GBL in effecting a cessation of impulse activity in all DA neuronal populations.

Effects of the administration of a low dose of apomorphine on $D A$ metabolism in discrete brain nuclei

Presynaptic and postsynaptic DA receptors presumably differ in their affinity for receptor agonists, with presynaptic receptors being selectively activated by low doses of agonists (Roth, 1979; Skirboll et al., 1979). This differential receptor sensitivity has been incorporated into an additional pharmacological/neurochemical strategy for mapping the distribution of DA autoreceptors (Bannon et al., 1983). The administration of a relatively low, presumably DA autoreceptor-selective, dose of apomorphine resulted in a nonuniform decrease in the concentration of HVA in the component nuclei of the amygdala and the subdivisions of the bed nucleus of the stria terminalis (Table 5).
Consistent with the findings of Bannon et al. (1983), low-dose apomorphine administration decreased the HVA content of the anterodorsal caudate nucleus, nucleus accumbens, and olfactory tubercle, but not of the medial prefrontal or cingulate cortex. In contrast, compared to HVA, the concentration of DOPAC exhibited greater variability and was less consistently altered by apomorphine; drug-induced decreases were observed only in the central amygdaloid nucleus, medial prefrontal cortex, and olfactory tubercle (data not shown). With the single exception of the olfactory tubercle, the concentration of 5-HIAA was not significantly altered by apomorphine administration in the brain nuclei or areas examined.

\section{Effects of the administration of pargyline on DOPA accumulation in discrete brain nuclei}

The activity of tyrosine hydroxylase has been shown to be under the influence of the intraneuronal concentration of catecholamines (Nagatsu et al., 1964). The rate of DA synthesis has been found to be inversely related to the intraneuronal DA concentration in all DA projection fields examined to date (Demarest and Moore, 1979; Bannon et al., 1981a). To ascertain whether end-product inhibition similarly regulates tyrosine hydroxylase 
activity in mesoamygdaloid and other limbic-projecting DA neuronal populations, we examined the influence of an increased intraneuronal DA concentration (produced by inhibiting the catabolism of DA) on the rate of DOPA accumulation in discrete brain nuclei or areas. The experimental results are summarized in Table 6. Consistent with previous reports (Demarest and Moore, 1979; Bannon et al., 1981a), monoamine oxidase inhibition produced a significant increase in the DA content and a concomitant decrease in DOPA accumulation in the caudate nucleus, olfactory tubercle, nucleus accumbens, and medial prefrontal cortex. Similar neuronal responses were observed in the majority of the component nuclei or subdivisions of the amygdala, septum, hippocampus, cerebrocortex, and bed nucleus of the stria terminalis. Pargyline administration also significantly increased the NE concentration in the majority of brain nuclei or areas examined. These results indicate that unlike autoreceptor-regulated neuronal DA synthesis, the end-product inhibition of tyrosine hydroxylase activity by the intraneuronal catecholamine concentration is a ubiquitously expressed regulatory propcrty of DA ncurons.

\section{Discussion}

In the CNS, the important presynaptic functions of neuronal DA synthesis, release, and impulse activity are regulated by distinct autoreceptor populations, with the degree of autoregulation of each function varying between different DA neuronal populations. The consequences of the activation of a given autoreceptor population is in part determined by the presence and occupancy of other autoreceptor populations. For example, in a neuron expressing all 3 mechanisms, neuronal DA synthesis is directly regulated by autoreceptors and indirectly influenced by perikarya-localized, impulse activity-modulating autoreceptors (Aghajanian and Bunney, 1977; Baring et al., 1980) and release-modulating autoreceptors (i.e., via end-product regulation) (Farnebo and Hamberger, 1971; Starke, 1981; Galloway et al., 1986). It has been postulated that a subset of mesocortical (Bannon et al., 1981a) and hypothalamic (Demarest and Moore, 1979) DA neurons lacks such autoreceptors and, further, that this regulatory feature imparts a unique physiology (Bannon et al., 1981 b; Chiodo et al., 1984) and pharmacology (Bannon et al., 1982) to these neuronal populations. The present study focused on the anatomical distribution of DA synthesis-modulating nerve terminal autoreceptors on mesoamygdaloid and other mesolimbic DA neuronal populations, using complementary approaches to study the biochemical response of DA nerve terminals isolated from the influence of neuronal feedback loops and/or intrinsic impulse activity. The examination and comparison of the results of complementary approaches were necessitated by the fact that each of the available in vivo techniques used to define the presence of DA synthesis-modulating autoreceptors (for a review, see Nowycky and Roth, 1978) has inherent assumptions and limitations. In the present study, 3 distinct methods were used to isolate DA nerve terminals from the confounding influences of impulse-mediated regulatory mechanisms, and DA neuronal response was estimated by 3 distinct biochemical end points.

An initial evaluation of the effect of a GBL-induced cessation of DA neuronal impulse activity on the DA content of discrete limbic projection ficlds indicated that in comparison to the wellcharacterized response in the olfactory tubercle, nucleus accumbens, caudate nucleus, cerebrocortex, and posterior pituitary, a lesser and more variable response was generally observed in the
Table 5. Effect of apomorphine $(50 \mu \mathrm{g} / \mathrm{kg}, \mathrm{s.c}$.) on the concentration of homovanillic acid (HVA) in discrete brain nuclei or areas

HVA concentration ( $\mathrm{ng} / \mathrm{mg}$ protein)

\begin{tabular}{lcc}
\cline { 2 - 3 } Brain nuclei or area & \multicolumn{1}{l}{ Saline } & \multicolumn{1}{l}{ Apomorphine } \\
\hline Amygdaloid & & \\
$\quad$ Central & $0.97 \pm 0.07(6)$ & $0.55 \pm 0.05(9)^{*}$ \\
Lateral & $1.3 \pm 0.13(6)$ & $0.90 \pm 0.08(9)^{*}$ \\
Basal & $0.45 \pm 0.02(6)$ & $0.39 \pm 0.05(9)$ \\
Medial & $0.11 \pm 0.02(5)$ & $0.097 \pm 0.01(7)$ \\
$\quad$ Basal posterior & $0.32 \pm 0.05(5)$ & $0.20 \pm 0.02(9)^{*}$ \\
Interstitial (bed) nucleus of stria terminalis & \\
$\quad$ Dorsal & $1.5 \pm 0.21(6)$ & $1.2 \pm 0.10(9)$ \\
$\quad$ Ventral & $1.8 \pm 0.20(6)$ & $1.3 \pm 0.11(9)^{*}$ \\
Hippocampus & & \\
$\quad$ Dorsal & $0.062 \pm 0.006$ & $0.061 \pm 0.004$ \\
Septal & & \\
$\quad$ Lateral & $0.88 \pm 0.04(5)$ & $0.74 \pm 0.05(9)$ \\
Cerebrocortical areas & & \\
$\quad$ Medial prefrontal & $0.40 \pm 0.05(6)$ & $0.31 \pm 0.03(9)$ \\
$\quad$ Cingulate & $0.54 \pm 0.04(5)$ & $0.58 \pm 0.04(9)$ \\
$\quad$ Pyriform & $0.52 \pm 0.09(5)$ & $0.45 \pm 0.03(9)$ \\
Caudate nucleus & $15.9 \pm 1.3(6)$ & $12.3 \pm 0.98(8)^{*}$ \\
Nucleus accumbens & $6.1 \pm 0.42(5)$ & $4.7 \pm 0.32(7)^{*}$ \\
Olfactory tubercle & $5.6 \pm 0.38(6)$ & $4.3 \pm 0.28(9)^{*}$ \\
\end{tabular}

Apomorphine was administered $30 \mathrm{~min}$ before animals were killed. Values represent means \pm SEM of the indicated (in parentheses) number of determinations per group.

component nuclei or subdivisions of the amygdala, bed nucleus of the stria terminalis, and septum. Moreover, the response of DA neurons innervating these subcortical limbic nuclei was inconsistently decreased by pretreatment with apomorphine. These results suggested that DA concentration represents a nonideal index of neuronal response to GBL and, furthermore, that the demonstration of an apomorphine-reversible increase in DA content by GBL is neither a necessary nor sufficient criterion for defining the presence of DA synthesis-modulating nerve terminal autoreceptors. Literature reports (Bannon et al., 1981a; Anden et al., 1983) and the results of this study (Tables 1,3) indicate that a GBL-induced increase in DA concentration is not invariably associated with an increased synthesis of DA. The accumulation of DA may reflect a continuation of DA synthesis accompanied by a drug-induced inhibition of DA release, as suggested by Bannon et al. (1981a), rather than the disinhibition of the tonic influence of synthesis-regulating autoreceptors. The blockade of the GBL-induced increase in DA concentration or synthesis by apomorphine is often offered as evidence supporting the involvement of a diminished activation of presynaptic DA receptors in mediating the effects of GBL. However, this cause-effect relationship has to be reevaluated in light of recent data demonstrating the direct, nonreceptor-mediated inhibition of synaptosomal tyrosine hydroxylase activity by apomorphine (Laschinski et al., 1984; Fowler et al., 1985) and the influence of apomorphine on DA concentration and synthesis secondary to actions on DA release-regulating autoreceptors (Saller and Salama, 1984; Galloway et al., 1986).

The noncquivalence of the effects of GBL and acute axotomy on DA concentration may relate to the confounding influences of halothane anesthesia, or perhaps an incomplete lesion produced by surgical, rather than pharmacological, means. Alter- 
Table 6. Effect of pargyline administration on the concentration of dopamine (DA) and norepinephrine (NE) and rate of DOPA accumulation in discrete brain nuclei or areas

\begin{tabular}{|c|c|c|c|}
\hline \multirow[b]{2}{*}{ Brain nuclei or area } & \multicolumn{3}{|c|}{ Catechol concentration ( $\%$ of control) } \\
\hline & $\mathrm{DA}$ & DOPA & $\mathrm{NE}$ \\
\hline \multicolumn{4}{|l|}{ Amygdaloid } \\
\hline Central & $131.0 \pm 11.5$ & $34.4 \pm 4.9$ & $128.9 \pm 7.7$ \\
\hline Lateral & $144.7 \pm 12.0$ & $38.2 \pm 3.3$ & $173.7 \pm 8.8$ \\
\hline Basal & $130.7 \pm 8.6$ & $33.8 \pm 6.3$ & $125.6 \pm 8.1$ \\
\hline Medial & $222.8 \pm 54.4$ & $30.2 \pm 6.2$ & $121.1 \pm 16.8$ n.s. \\
\hline Cortical & $112.7 \pm 9.8$ n.s. & $33.2 \pm 2.1$ & $131.9 \pm 7.7$ \\
\hline Posterior & $125.1 \pm 10.3$ & $32.1 \pm 6.8$ & $130.3 \pm 7.2$ \\
\hline Medial posterior & $89.5 \pm 10.7$ n.s. & $30.0 \pm 9.5$ & $105.9 \pm 3.1$ n.s. \\
\hline Basal posterior & $192.2 \pm 11.2$ & $36.6 \pm 6.7$ & $150.7 \pm 9.1$ \\
\hline Anterior amygdaloid area & $195.6 \pm 30.1$ & $38.7 \pm 5.1$ & $136.3 \pm 5.6$ \\
\hline \multicolumn{4}{|c|}{ Interstitial (bed) nucleus of stria terminalis } \\
\hline Dorsal & $178.5 \pm 29.0$ & $50.8 \pm 7.7$ & $137.1 \pm 7.6$ \\
\hline Ventral & $149.2 \pm 12.9$ & $45.7 \pm 2.2$ & $133.2 \pm 7.3$ \\
\hline \multicolumn{4}{|l|}{ Septal } \\
\hline Lateral & $127.7 \pm 6.4$ & $43.2 \pm 2.3$ & $177.8 \pm 17.6$ \\
\hline Medial & $128.4 \pm 7.2$ & $35.5 \pm 2.6$ & $146.5 \pm 15.4$ \\
\hline \multicolumn{4}{|l|}{ Hippocampus } \\
\hline Dorsal & $164.8 \pm 25.5$ & $35.3 \pm 2.9$ & $151.7 \pm 11.1$ \\
\hline Ventral & n.a. & n.a. & n.a. \\
\hline Nucleus accumbens & $164.1 \pm 32.0$ & $40.5 \pm 8.0$ & $162.9 \pm 27.8$ \\
\hline Olfactory tubercle & $135.8 \pm 9.0$ & $38.1 \pm 3.6$ & n.a. \\
\hline \multicolumn{4}{|l|}{ Cerebral cortex } \\
\hline Medial prefrontal & $187.3 \pm 15.0$ & $39.2 \pm 2.9$ & $159.6 \pm 8.7$ \\
\hline Cingulate & $232.8 \pm 30.9$ & $46.2 \pm 6.5$ & $171.6 \pm 12.1$ \\
\hline Entorhinal & $209.9 \pm 13.0$ & $30.0 \pm 2.1$ & $142.9 \pm 3.9$ \\
\hline Pyriform & $202.0 \pm 23.0$ & $40.9 \pm 3.1$ & $140.4 \pm 4.8$ \\
\hline \multicolumn{4}{|l|}{ Basal ganglia } \\
\hline Dorsolateral caudate nucleus & $145.0 \pm 10.7$ & $32.4 \pm 1.4$ & $104.2 \pm 7.9$ n.s. \\
\hline Ventromedial caudate nucleus & $151.6 \pm 8.5$ & $47.1 \pm 3.3$ & n.a. \\
\hline Posterior caudate-putamen & $139.0 \pm 9.9$ & $49.0 \pm 12.4$ & $123.9 \pm 13.4$ n.s. \\
\hline
\end{tabular}

Catechol concentrations from pargyline-treated subjects $(n=6$ or 7$)$ are expressed as a percentage of control values derived from vehicle-injected animals $(n=5-7)$. Animals were administered either pargyline (75 mg/kg, i.p.) or its vehicle $(1 \mathrm{ml} / \mathrm{kg}$, i.p.) $180 \mathrm{~min}$ prior to being killed and NSD-1015 (100 mg/kg, i.p.) 30 min prior to death. Unless indicated otherwise (n.s.), pargyline administration significantly $(p<0.05)$ increased the concentration of DA and NE and decreased DOPA accumulation.

n.a., Not assaycd.

n.s., $p>0.05$.

natively, the transection of NE or other non-DA neurons in the axotomy of DA neurons by surgical, but not GBL-induced, techniques may alter the observed response of DA neurons. It is of interest that Kehr and coworkers (1977) have reported only slight increases in DA content, accompanied by significant increases in DOPA accumulation, in relatively large DA projection fields $30 \mathrm{~min}$ after complete transverse hemitransection of the rat brain. These results further question the value of DA concentration determinations as a measure of the gencralized response of distinct DA neuronal populations to a cessation of intrinsic impulse activity.

The NSD-1015-induced accumulation of DOPA (i.e., in vivo tyrosine hydroxylase activity) was evaluated as a more direct index of DA-synthetic activity in mapping the limbic distribution of DA synthesis-modulating nerve terminal autoreceptors. The greater potency of inhibition by apomorphine of the GBL-induced increase in DOPA accumulation versus that in DA concentration, and the differential potencies of a series of DA agonists to inhibit each effect of GBL (Feenstra et al., 1983) illustrate the nonequivalence of these 2 measures of presynaptic DA activity as end points of DA neuronal response to GBL. We have proposed that if profound alterations in the synaptic cleft content of the endogenous affector (i.e., DA) of tonically active nerve terminal autoreceptors does not alter DA synthesis, then such autoreceptors are not functionally present. Using this GBL-DOPA accumulation model and this operational definition, we obtained results for the caudate nucleus, olfactory tubcrcle, nucleus accumbens, median emincnce, and medial prefrontal cortex (Tables 2,3 ) that were in excellent agreement with the differential localization of DA synthesis-regulating autoreceptors on terminals of these distinct DA neuronal populations, as reported by other investigators (Demarest and Moore, 1979; Bannon et al., 1981 a; Demarest et al., 1983). The administration of GBL did not increase the rate of DOPA accumulation in any of the 8 amygdaloid nuclei or in the anterior amygdaloid area, suggesting that the varying DA innervation of the amygdaloid nuclei is not associated with synthesis-modulating autoreceptors. In fact, GBL administration significantly decreased the 
accumulation of DOPA in the central and basal amygdaloid nuclei. This nuclei-specific decrease in DA synthesis, associated with a diminished synaptic DA content, might reflect the presence of tonically excitatory synthesis-modulating autoreceptors or, alternatively, the unhindered influence of the end-product inhibition of tyrosine hydroxylase activity by the increasing intracellular concentration of DA evoked by GBL. The first possibility is weakened somewhat by the fact that apomorphine pretreatment further decreased, rather than increased, DOPA accumulation (Table 3). The demonstration of the end-product inhibition of DOPA accumulation by an enhanced intraneuronal content of DA in these nuclei (Table 6) reinforces the latter possibility. The autoreceptor-regulated DA neurons in the posterior caudate-putamen were sampled immediately dorsal to the nonautoregulated central and lateral amygdaloid nuclei, and thus illustrate the need for the accurate delineation and dissection of contiguous brain structures in mapping the neuronal population-specific distribution of synthesis-modulating autoreceptors.

The uniform lack of synthesis-modulating autoreceptors on terminals of populations of mesoamygdaloid DA neurons would appear to be causally unrelated to their differential rates of biochemically estimated impulse activity (Kilts and Anderson, 1986), an association postulated for populations of mesocortical DA neurons (Bannon et al., 1981b). It is tempting to speculate that the uniform absence of synthesis-modulating autoreceptors on mesoamygdaloid DA neurons may be functionally related to a uniform nonassociation between DA receptors and adenylate cyclase-catalyzed cyclic AMP production in the amygdala (Kilts et al., 1984b). This functional relationship is plausible, as El Mestikawy et al. (1986) and El Mestikawy and Hamon (1986) have reported that the regulation of tyrosine hydroxylase activity by presynaptic autoreceptors may involve modulation of the cyclic AMP-dependent phosphorylation of the enzyme.

A lack of DA synthesis-modulating autoreceptors on DA nerve tcrminals is apparently not unique to mesoamygdaloid D $\Lambda$ neurons, but represents, rather, a generalized regulatory property of DA neuronal populations projecting to subcortical limbic structures. Populations of DA neurons projecting to the lateral and medial septal nuclei, subdivisions of the bed nucleus of the stria terminalis and hippocampus, and the paraventricular hypothalamic nucleus similarly fail to respond to a decrease in the synaptic content of DA with an increased rate of DOPA accumulation (Table 3 ). The possibility exists that DA synthesis in DA neurons terminating in the amygdala and other limbic structures may be under the regulatory influence of nerve terminal autoreceptors, but that the influence is of a phasic, rather than tonic, nature, dependent on the rate of neuronal impulse activity, a possibility not tested by this model. Tepper and coworkers (1984) have shown that the receptor-mediated autoinhibition of another presynaptic function (i.e., neuronal DA release) is a function of neuronal firing rate.

Of the various DA cell body-rich areas of the ventromedial mesencephalon, the substantia nigra-pars compacta and the lateral and medial VTA exhibited a relatively high rate of in vivo tyrosine hydroxylase activity. Using animals in which the striatonigral feedback loops were lesioned, Argiolas and coworkers (1982) demonstrated that DA synthesis in the substantia nigra was under the inhibitory influence of local autorcecptors. The findings of the present study further resolve this receptor-mediated autoinhibition to the substantia nigra-pars compacta, and not to the DA cell bodies and their processes localized in the pars reticulata and pars lateralis. Conversely, DA synthesis in the lateral and medial VTA, containing the cell bodies of origin of the DA innervation of limbic and cerebrocortical brain structures, is apparently not similarly regulated by autoreceptors. The distribution of synthesis-regulating autoreceptors in the ventromedial mesencephalon parallels that of the hinding site density of selective radioligands of the $\mathrm{D}_{2} \mathrm{DA}$ receptor subtype (Boyson et al., 1986). This correlation indirectly supports the contention that DA synthesis-regulating autoreceptors are of the $\mathrm{D}_{2}$ subtype (Tissari et al., 1983). However, the distribution of DA synthesisregulating autoreceptors in DA neuronal projection fields (particularly limbic) does not covary with that of $\mathrm{D}_{2}$ receptors-a predictable noncorrelation in light of the fact that $D_{2}$ receptors are involved in the regulation of other presynaptic and postsynaptic functions of DA neurons, such as DA release (Dwoskin and Zahniser, 1986) and adenylate cyclase activity (Stoof and Kebabian, 1981).

A critical assumption inherent to the use of the GBL-DOPA accumulation model in mapping the distribution of DA synthesis-modulating autoreceptors is that GBL administration produces a universal cessation of impulse activity in all DA neurons in the CNS. As the mechanism underlying this action of GBL is not currently known, and in light of the infeasible scope of the electrophysiological experiments needed to directly test this assumption, it is unlikely that this contention will be substantiated. The apparent lack of DA synthesis-modulating autoreceptors on terminals of mesoamygdaloid and other mesolimbic DA neuronal populations defined by this model may instead reflect a relative insensitivity of these neurons to GBL. This possibility was examined by studying the responses of these neurons to a cessation of impulse activity resulting from their surgical, rather than pharmacological, transection. A comparison of the acute and prolonged effects of unilateral MFB transection on the DA concentration of distinct projection fields indicated an excellent agreement with the effects of axotomy on mesostriatal and mesocortical DA terminals reported by other investigators, and documented a profound, widespread lesion of ascending DA and NE neurons, respectively. The comparison of the response (DA synthesis) of nerve terminals ipsilateral to the side of the transection to the corresponding contralateral field is confounded by the degree to which neurons decussate in a given projection system. The contribution of this variable is minor for mesoamygdaloid DA neurons, as only approximately $2 \%$ of neurons projecting from the ventromedial mesencephalon to the amygdala decussate in the rat (Swanson, 1982). The results of these experiments further support the absence of synthesis-regulating autoreceptors on DA terminals in the component nuclei of the amygdala, as well as in other subcortical limbic structures. Interestingly, several cortical limbic structures (i.e., ventral hippocampus and cingulate cortex) exhibited a significant lesion-induced increase in DOPA accumulation. The inferred presence of tonically inhibitory DA synthesis-modulating autoreceptors in the cingulate cortex is consistent with the results of the GBL-DOPA accumulation experiments, while the effect of GBL on DOPA accumulation in the ventral hippocampal subfield was not examined. The possibility exists that DA synthesis in populations of DA neurons projecting to the dorsal versus the ventral hippocampus is differentially regulated by tonically inhibitory terminal autoreceptors. The remarkable parallel between the effects of GBL administration and of MFB transection on DA synthesis in distinct projection fields of diverse DA neuronal populations supports the ability of GBL to 
effect a universal cessation of firing rate in all DA neurons.

The anterior striatum has been subdivided into dorsolateral (nonlimbic) and ventromedial (limbic) parts on the basis of their differential innervation by limbic brain structures and sensorimotor cortex, as well as their differential projection to distinct fields in the globus pallidus (Kelley et al., 1982; Nauta, 1986). The rich dopaminergic innervation of the striatum also conforms to this subdivision, as DA neurons of the limbic and nonlimbic striatum differ in the localization of their cell bodies of origin in the ventromedial mesencephalon (Beckstead et al., 1979), their role in modulating exploratory locomotor behavior (Ahlenius et al., 1987), and their susceptibility to degeneration in weaver mutants (Roffler-Tarlov and Graybiel, 1984). However, the rate of DOPA accumulation in both the dorsolateral and ventromedial caudate nucleus was significantly increased by both GBL and surgical axotomy, suggesting that tonically inhibitory, nerve terminal autoreceptors are operative in regulating DA synthesis in both DA projection fields. The possibility exists that autoregulatory distinctions between DA neuronal populations within the striatum may adhere to a striosomal architecture, as has been demonstrated for tyrosine hydroxylase (Graybiel et al., 1987) and DA receptors (Loopuijt et al., 1987).

Several points are worth mentioning concerning the differential distribution of DA synthesis-modulating autoreceptors on terminals of populations of mesocortical DA neurons. The observed lack of effect of GBL administration or axotomy on DOPA accumulation in the medial prefrontal cortex is wholly consistent with the contention of Bannon and coworkers (1981a) that this subset of mesocortical DA neurons lacks such terminal autoreceptors. However, in contrast to the findings of these investigators, both methods of isolating DA terminals in the anterior cingulate cortex resulted in significant increases in estimated DA synthesis in this subset of DA neurons. The reason for this discrepancy is currently unknown, but may relate to differences in the mediolateral or anterioposterior coordinates of tissue dissection. No evidence was found supporting the localization of DA synthesis-modulating autoreceptors on DA neurons innervating either of the allocortical regions examined.

Administration of the monoamine oxidase inhibitor pargyline resulted in a significant increase in the concentration of DA and $\mathrm{NE}$ in the majority of brain nuclei or areas examined, which was accompanied by a profound decrease in the rate of DOPA accumulation. Therefore, tyrosine hydroxylase activity in DA neuronal populations innervating the component nuclei of the amygdala and septum, and the subdivisions of the bed nucleus of the stria terminalis and hippocampus, appears to be under the regulatory influence of end-product inhibition by the intraneuronal DA concentration - a regulatory property shared with mesostriatal, tuberoinfundibular, tuberohypophyseal, mesocortical, retinal, and substantia nigra DA neurons (Roth et al., 1973; Demarest and Moore, 1979; Bannon et al., 1981a; Argiolas et al., 1982). The concomitant pargyline-induced increases in NE concentration may contribute to the observed decrease in tyrosine hydroxylase activity, though this contribution is probably minor, as NSD-1015-induced DOPA accumulation predominantly reflects the synthesis of DA in the projection fields examined.

The possibility exists that an increase in DOPA accumulation in the amygdaloid complex, resulting from a GBL-induced disinhibition of synthesis-modulating terminal autoreceptors, may have been obscured by the end-product inhibition of DA synthesis resulting from a drug-induced increase in the intraneu- ronal concentration of DA. While the time course of the effects of GBL administration on the DA content and rate of DOPA accumulation of discrete amygdaloid nuclei was not examined for a possible temporal dissociation of drug effects, the results of the effects of acute surgical axotomy on these 2 measures argues against this possible confound. Acute axotomy, like GBL administration, failed to increase the rate of DOPA accumulation in the amygdaloid complex, yet, unlike GBL administration, did not increase the DA content of mesoamygdaloid DA neurons.

On initial examination, the interpretation of the DA neuronal population-specific effects of a relatively low, presumably DA autoreceptor-selective dose $(50 \mu \mathrm{g} / \mathrm{kg}, \mathrm{s.c}$.) of apomorphine on DA metabolism would appear to be in striking contrast to the distribution of synthesis-modulating autoreceptors mapped by the GBL-DOPA accumulation and MFB transection-DOPA accumulation models. The results, in the present study, of the application of this apomorphine-DA metabolism model suggest that some DA neuronal populations innervating the component nuclei or subdivisions of the amygdala, septum, bed nucleus of the stria terminalis, hippocampus, and cerebrocortex are under the regulatory influence of autoreceptors. However, this apomorphine-DA metabolism model presumes that all presynaptic DA receptors have a higher affinity for DA compared to postsynaptic receptors, and uses an end point of neuronal response that reflects the net influence of a multitude of presynaptic functions (Westerink, 1985). Therefore, the effects of apomorphine on HVA and DOPAC concentrations may reflect actions on DA autoreceptor populations other than those directly regulating synthesis (e.g., release- or impulse activity-modulating), which are of similar high affinity, yet also differ in their neuronal population distribution. Alternatively, the apomorphine-induced decrease in HVA and DOPAC concentrations may reflect a direct, nonreceptor-mediated inhibition of tyrosine hydroxylase activity reported for even low concentrations of apomorphine (Laschinski ct al., 1984; Fowler ct al., 1985). The decreasc in DOPAC and HVA concentrations may also reflect the influence of postsynaptic DA receptor-mediated neuronal feedback produced by a dose of apomorphine in excess of that effecting a selective activation of presynaptic DA autoreceptors. From these results, it is concluded that uncertainties concerning the site and mechanisms of action of apomorphine on DA neurons and the specific presynaptic functions reflected in changes in the concentrations of DOPAC and HVA render use of the apomorphine-DA metabolism model of questionable value in mapping the distribution of DA synthesis-modulating autoreceptors. This point highlights the fact that the conclusion as to the presence or absence of nerve terminal-localized, DA synthesis-modulating autoreceptors is dependent on the preparation and the index of neuronal response chosen for study, and probably underlies contradictory reports concerning the localization of such autoreceptors on mesoprefontal cortical DA terminals (Fadda et al., 1984; Galloway et al., 1986).

In concluding, we have found that the findings and implications of the present study have an impact on the physiology and pharmacology of DA neurons in the CNS and their organization into populations or systems. First, an absence of DA synthesismodulating autoreceptors is not a unique regulatory property of terminals of subsets of mesocortical and hypothalamic DA neuronal populations, but rather reflects the state of synthesis regulation in DA neurons innervating the subcortical limbic system. The uniform absence of such autoreceptors on me- 
soamygdaloid DA terminals does not parallel the heterogeneous distribution of DA (Kilts and Anderson, 1986), nor the differential rates of biochemically estimated DA neuronal activity between the component nuclei of the amygdala (Kilts and Anderson, 1987), nor the widely varying degree of tolerance observed in the response of populations of mesoamygdaloid DA neurons to haloperidol following chronic drug administration (C. D. Kilts and T. D. Ely, unpublished observations). The significance of the lack of this receptor-mediated autoinhibition of DA synthesis to the physiology and pharmacology of mesoamygdaloid DA neurons is therefore currently unknown. The results of the present experiments question the breadth of the influence of nerve terminal autoreceptors in regulating the synthetic activity of DA neurons in the CNS, and suggest that the absence of this regulatory mechanism represents the functional norm rather than the exception. Second, these results further emphasize that the nucleus accumbens and olfactory tubercle do not represent or reflect DA neurotransmission in the limbic system. The generalization of the results of physiological, pharmacological, and behavioral experiments involving DA neurons in the nucleus accumbens and olfactory tubercle to the role of DA in the limbic system is a long- and often-practiced convenience that presumes a homogeneity of function and pharmacology of all DA neurons projecting to limbic brain structures. This presumption is not supported by these and other (Scatton, 1981; Anderson and Rebec, 1986; Kilts and Anderson, 1987) data. Moreover, in contrast to the amygdala, septum, hippocampus, and bed nucleus of the stria terminalis, brain structures central to virtually every definition of the anatomical and functional organization of the limbic system, the nucleus accumbens, and olfactory tubercle may be better defined as striatal structures, comprising a conduit by which the limbic system may influence the striatum (Heimer, 1978). It is our contention that the informative study of the role of DA neurotransmission in the function, dysfunction, and pharmacology of the limbic systcm must bc conducted at the level of the component nuclei or subfields of the amygdala, septum, bed nucleus of the stria terminalis, and hippocampus. Third, these results may furnish a physiological basis for the putative pharmacological nonsuccess (Meltzer, 1980; Ferrier, 1982; Levy et al., 1984) of the clinical use of low doses of DA-receptor agonists in the treatment of schizophrenia. Such a strategy is predicated on diminished DA neurotransmission, resulting from a selective activation of inhibitory presynaptic autoreceptors (Smith et al., 1977). However, at least one such substrate for drug action, the autoreceptor population regulating the synthesis (availability) of DA for synaptic release, is absent from populations of limbic projecting DA neurons, which are thought to be critically involved in the pharmacotherapy and pathology of schizophrenia (Matthysse, 1973; Stevens, 1973). Whether other autoreceptor populations modulating neuronal DA release or DA neuronal impulse activity are similarly absent from the DA neuronal populations innervating the limbic system will further elucidate the significance of this physiological/pharmacological relationship.

\section{References}

Aghajanian, G. K., and B. S. Bunney (1977) Dopamine "autoreceptors": Pharmacological characterization by microiontophoretic single cell recording studies. Naunyn Schmiedebergs Arch. Pharmacol. 297: $1-7$.

Ahlenius, S., V. Hillegaart, G. Thorell, O. Magnusson, and C. J. Fowler (1987) Suppression of exploratory locomotor activity and increase in dopamine turnover following the local application of cis-flupen- thixol into limbic projection areas of the rat striatum. Brain Res. 402: $131-138$

Anden, N.-E., M. Grabowska-Anden, and B. Liljenberg (1983) Demonstration of autoreceptors on dopamine neurons in different brain regions of rats treated with gammabutyrolactone. J. Neural Trans. 58: 143-152

Anderson, C. M., D. L. Knight, L. E. Elliott, T. D. Ely, and C. D. Kilts (1985) Pharmacology and regulation of mesoamygdaloid dopamine neurons. Soc. Neurosci. Abstr. 11: 1206.

Anderson, G. D., and G. V. Rebec (1986) Differential response of amygdaloid neurons to clozapine and haloperidol: Effects of repeated administration. Pharmacol. Biochem. Behav. 24: 1561-1566.

Argiolas, A., M. R. Melis, F. Fadda, and G. L. Gessa (1982) Evidence for dopamine autoreceptors controlling dopamine synthesis in the substantia nigra. Brain Res. 234: 177-181.

Bannon, M. J., R. L. Michaud, and R. H. Roth (1981a) Mesocortical dopamine neurons: Lack of autoreceptors modulating dopamine synthesis. Mol. Pharmacol. 19: 270-275.

Bannon, M. J., E. B. Bunney, and R. H. Roth (1981b) Mesocortical dopamine neurons: Rapid transmitter turnover compared to other brain catecholamine systems. Brain Res. 218: 376-382.

Bannon, M. J., J. R. Reinhard, Jr., E. B. Bunney, and R. H. Roth (1982) Unique response to antipsychotic drugs is due to absence of terminal autoreceptors in mesocortical dopamine neurones. Nature 296:444 446.

Bannon, M. J., M. E. Wolf, and R. H. Roth (1983) Pharmacology of dopamine neurons innervating the prefrontal, cingulate, and piriform cortices. Eur. J. Pharmacol. 91: 119-125.

Baring, M. D., J. R. Walters, and N. Eng (1980) Action of systemic apomorphine on dopamine cell firing after neostriatal kainic acid lesions. Brain Res. 181: 214-218.

Bayer, S. A. (1980) Quantitative ${ }^{3} \mathrm{H}$-thymidine radiographic analyses of neurogenesis in the rat amygdala. J. Comp. Neurol. 194: 845-875.

Beckstead, R. M., V. B. Domesick, and W. J. H. Nauta (1979) Efferent connections of the substantia nigra and ventral tegmental area in the rat. Brain Res. 175: 191-217.

Ben-Ari, Y., and J. S. Kelly (1976) Dopamine evoked inhibition of single cells of the feline putamen and basolateral amygdala. J. Physiol. (Lond.) 256: 1-21.

Ben-Ari, Y., R. E. Zigmond, and K. E. Moore (1975) Regional distribution of tyrosine hydroxylase norepinephrine and dopamine within the amygdaloid complex of the rat. Brain Res. 87: 96-101.

Björklund, A., and O. Lindvall (1975) Dopamine in dendrites of subslantia nigra neurons: Suggestions for a role in dendritic terminals. Brain Res. 83: 531-537.

Boyson, S. J., P. McGonigle, and P. B. Molinoff (1986) Quantitative autoradiographic localization of the $D_{1}$ and $D_{2}$ subtypes of dopamine receptors in rat brain. J. Neurosci. 6: 3177-3188.

Brodal, A. (1947) The amygdaloid nucleus in the rat. J. Comp. Neurol. 87: 1-16.

Brownstein, M., J. M. Saavedra, and M. Palkovits (1974) Norepinephrine and dopamine in the limbic system of the rat. Brain Res. 79: 431-436.

Carlsson, A., J. N. Davis, W. Kehr, M. Lindqvist, and C. V. Atack (1972) Simultaneous measurement of tyrosine and tryptophan hydroxylase activities in brain in vivo using an inhibitor of the aromatic amino acid decarboxylase. Naunyn Schmiedebergs Arch. Pharmacol. 275: 153-168.

Charriere, B., F. Daudet, B. Guibert, C. Barberis, and V. Leviel (1983) "In situ" release of dopamine in the nucleus amygdaloideus centralis. Brain Res. 27 1: 386-387.

Chiodo, L. A., M. J. Bannon, A. A. Grace, R. H. Roth, and B. S. Bunney (1984) Evidence for the absence of impulsc-rcgulating somatodendritic and synthesis-modulating nerve terminal autoreceptors on subpopulations of mesocortical dopamine neurons. Neuroscience 12:116.

Clement-Cormier, Y. C., and G. A. Robison (1977) Adenylate cyclase from various dopaminergic areas of the brain and the action of antipsychotic drugs. Biochem. Pharmacol. 26: 1719-1722.

Dahlstrom, A., and K. Fuxe (1964) Evidence for the existence of monoamine neurons in the central nervous system. I. Demonstration of monoamines in the cell bodies of brain stem neurons. Acta Physiol. Scand. (Suppl. 232) 64: 1-55.

Dawson, T. M., D. R. Gehlert, R. T. McCabe, A. Barnett, and J. K. Wamsley (1986) D-1 dopamine receptors in the rat brain: A quan- 
titative autoradiographic analysis. J. Neurosci. 6: 2352-2365.

Demarest, K. I., and K. E. Moore (1979) Comparison of dopamine synthesis regulation in the terminals of nigrostriatal, mesolimbic, tuberoinfundibular and tuberohypophyseal neurons. J. Neural Trans. 46: $263-277$.

Demarest, K. T., K. L. Lawson-Wendling, and K. E. Moore (1983) $d$-Amphetamine and $\gamma$-butyrolactone alteration of dopamine synthesis in the terminals of nigrostriatal and mesolimbic neurons. Possible role of various autoreceptor sensitivities. Biochem. Pharmacol. 32: 691-697.

Dubois, A., M. Savasta, O. Curet, and B. Scatton (1986) Autoradiographic distribution of the $D_{1}$ agonist $\left[{ }^{3} \mathrm{H}\right] \mathrm{SKF} 38393$ in the rat brain and spinal cord. Comparison with the distribution of $\mathrm{D}_{2}$ dopamine receptors. Neuroscience 19: 125-137.

Dunn, J. D., and J. Whitener (1986) Plasma corticosterone responses to electrical stimulation of the amydgaloid complex: Cytoarchitectural specificity. Neuroendocrinology 42: 211-217.

Dwoskin, L. P., and N. R. Zahniser (1986) Robust modulation of $\left[{ }^{3} \mathrm{H}\right]$ dopamine release from rat striatal slices by $\mathrm{D}_{2}$ dopamine receptors. J. Pharmacol. Exp. Ther. 239: 442-453.

El Mestikawy, S., and M. Hamon (1986) Is dopamine-induced inhibition of adenylate cyclase involved in the autoreceptor-mediated negative control of tyrosine hydroxylase in striatal dopaminergic terminals. J. Neurochem. 47: 1425-1433.

El Mestikawy, S., J. Glowinski, and M. Hamon (1986) Presynaptic dopamine autoreceptors control tyrosine hydroxylase activation in depolarized striatal dopaminergic terminals. J. Neurochem. 46: 1222.

Fadda, F., G. L. Gessa, M. Marcou, E. Mosca, and Z. Rossetti (1984) Evidence for dopamine autoreceptors in mesocortical dopamine neurons. Brain Res. 293: 67-72.

Fallon, J. H., D. A. Koziell, and R. Y. Moore (1978) Catecholamine innervation of the basal forebrain. II. Amygdala, suprarhinal cortex and entorhinal cortex. J. Comp. Neurol. 180: 509-532.

Farnebo, L.-O., and B. Hamberger (1971) Drug-induced changes in the release of ${ }^{3} \mathrm{H}$-monoamines from field-stimulated rat brain slices. Acta Physiol. Scand. (Suppl. 371) 84: 35-44.

Feenstra, M. G. P., C. Summers, J. H. Goedemoed, J. B. de Vries, H. Rollema, and A. S. Horn (1983) A comparison of the potencies of various dopamine receptor agonists in models for pre- and postsynaptic receptor activity. Naunyn Schmiedebergs Arch. Pharmacol. 324 : 108-115.

Fekete, M. I. K., J. P. Herman, B. Kanyicska, and M. Palkovits (1979) Dopamine, noradrenaline and 3,4-dihydroxyphenylacetic acid (DOPAC) levels of individual brain nuclei, effects of haloperidol and pargyline. J. Neural Trans. 45: 207-218.

Ferrier, I. N. (1982) Clinical and hormonal effects of apomorphine (APO) in acute and chronic schizophrenia. Br. J. Psychiatry 140: 204.

Fowler, C. J., G. Thorell, M. Anderson, and O. Magnusson (1985) Is inhibition of striatal synaptosomal tyrosine hydroxylation by dopamine agonists a measure of dopamine autoreceptor function? Naunyn Schmiedebergs Arch. Pharmacol. 331: 12-19.

Galloway, M. P., M. E. Wolf, and R. H. Roth (1986) Regulation of dopamine synthesis in the medial prefrontal cortex is mediated by release modulating autoreceptors: Studies in vivo. J. Pharmacol. Exp. Ther. 236: 689-698.

Graybiel, A. M., E. C. Hirsch, and Y. A. Agid (1987) Differences in tyrosine hydroxylase-like immunoreactivity characterize the mesostriatal innervation of striosomes and extrastriosomal matrix at maturity. Proc. Natl. Acad. Sci. USA 84: 303-307.

Heimer, L. (1978) The olfactory cortex and the ventral striatum. In Limbic Mechanisms, the Continuing Evolution of the Limbic System Concept, K. E. Livingston and O. Hornykiewicz, eds., pp. 95-187, Plenum, New York.

Hirano, M., J. S. Kim, M. Saito, H. Uchimura, M. Ito, and T. Nakahara (1978) Monoamine oxidase activities for serotonin and tyramine in individual limbic and lower brain stem nuclei of the rat. J. Neurochem. 30: 263-267.

Humphrey, T. (1936) The telencephalon of the bat. I. The noncortical nuclear masses and certain pertinent fiber connections. J. Comp. Neurol. 65: 603-711.

Jacobowitz, D. M., and M. Palkovits (1974) Topographic atlas of catecholamine and acetylcholinesterase-containing neurons in the rat brain. J. Comp. Neurol. 157: 13-28.

Javitch, J. A., S. M. Strittmatter, and S. H. Snyder (1985) Differential visualization of dopamine and norepinephrine uptake sites in rat brain using $\left[{ }^{s} \mathrm{H}\right]$ mazindol autoradiography. J. Neurosci. 5: 1513-1521

Kehr, W., A. Carlsson, and M. Lindquist (1977) Catecholamine synthesis in rat brain after axotomy: Interaction between apomorphine and haloperidol. Naunyn Schmiedebergs Arch. Pharmacol. 297: 111117

Kelley, A. E., V. B. Domesick, and W. J. H. Nauta (1982) The amygdalostriatal projection in the rat - an anatomical study by anterograde and retrograde tracing methods. Neuroscience $7: 615-630$.

Kilts, C. D., and C. M. Anderson (1986) The simultaneous quantifcation of dopamine, norepinephrine and epinephrine in micropunched rat brain nuclei by on-line trace enrichment HPLC with electrochemical detection: Distribution of catecholamines in the limbic system. Neurochem. Int. 9: 437-445.

Kilts, C. D., and C. M. Anderson (1987) Mesoamygdaloid dopamine neurons: Differential rates of dopamine turnover in discrete amygdaloid nuclei of the rat brain. Brain Res. 416: 402-408.

Kilts, C. D., and L. A. Bero (1984) Quantitative determination of 5-hydroxytryptophan in dissected brain regions by on-line trace enrichment HPLC with electrochemical detection. Life Sci. 35: 87-95.

Kilts, C. D., G. R. Breese, and R. B. Mailman (1981) Simultaneous quantification of dopamine, 5-hydroxytryptamine and four metabolically related compounds by means of reversed-phase high-performance liquid chromatography with electrochemical detection. J. Chromatogr. 225: 347-357.

Kilts, C. D., M. Gooch, and K. Knopes (1984a) Quantification of plasma catecholamines by on-line trace enrichment HPLC with electrochemical detection. J. Neurosci. Methods 11: 257-273.

Kilts, C. D., C. M. Anderson, D. W. Schulz, and R. B. Mailman (1984b) Mesoamygdaloid dopamine neurons: Some unusual properties. Soc. Neurosci. Abstr. 10: 881 .

Klemm, N., L. C. Murrin, and M. J. Kuhar (1979) Neuroleptic and dopamine receptors: Autoradiographic localization of $\left[{ }^{3} \mathrm{H}\right]$ spiperone in rat brain. Brain Res. 169: 1-9.

Kluver, H., and E. Barrera (1953) A method for the combined staining of cells and fibers in the nervous system. J. Neuropathol. Exp. Neurol. 12: 400-403.

Koch, D. D., and P. T. Kissinger (1980) Determination of serotonin in serum and plasma by liquid chromatography with precolumn sample enrichment and electrochemical detection. Anal. Chem. 52: 2729.

Konig, J. F. R., and R. A. Klippel (1963) The Rat Brain: A Stereotaxic Atlas of the Forebrain and Lower Parts of the Brain Stem, Williams \& Wilkins, Baltimore, MD.

Laschinski, G., B. Kittner, and M. Brautigam (1984) Inhibition of striatal tyrosine hydroxylase by low concentrations of apomorphine. Naunyn Schmiedebergs Arch. Pharmacol. 327: 114-118.

Levy, M. I., B. M. Davis, R. C. Mohs, K. S. Kendler, A. A. Mathe, G. Trigos, T. B. Horvath, and K. L. Davis (1984) Apomorphine and schizophrenia. Arch. Gen. Psychiatry 4I: 520-524.

Lindvall, O., and A. Björklund (1983) Dopamine- and norepinephrine-containing neuron systems: Their anatomy in the rat brain. In Chemical Neuroanatomy, P. C. Emson, ed., pp. 229-256, Raven, New York.

Loopuijt, L. D., J. B. Sebens, and J. Korf (1987) A mosaic-like distribution of dopamine receptors in rat neostriatum and its relationship to striosomes. Brain Res. 405: 405-408.

Lowry, O. H., N. J. Rosebrough, A. L. Farr, and R. J. Randall (1951) Protein measurement with the Folin phenol reagent. J. Biol. Chem. 193: 265-275

Matthysse, S. (1973) Antipsychotic drug actions: A clue to the neuropathology of schizophrenia? Fed. Proc. 32: 200-205.

Meltzer, H. Y. (1980) Relevance of dopamine autoreceptors for psychiatry: Preclinal and clinical studies. Schizophr. Bull. 6: 456-475.

Millhouse, O. E., and J. DeOlmos (1981) Aspects of the neuronal organization of the amygdala. In The Amygdaloid Complex. INSERM Symposium No. 20, Y. Ben-Ari, ed., pp. 33-43, Elsevier/North-Holland, New York.

Nagatsu, T., M. Levitt, and S. Undenfriend (1964) Tyrosine Hydroxylase - the initial step in norepinephrine biosynthesis. J. Biol. Chem. 239: 2910-2917.

Nauta, W. J. H. (1986) Circuitous connections linking cerebral cortex, limbic system, and corpus striatum. In The Limbic System: Functional Organization and Clinical Disorders, B. K. Doane and K. E. Livingstron, eds., pp. 43-54, Raven, New York. 
Nowycky, M. C., and R. H. Roth (1978) Dopaminergic neurons: Role of presynaptic receptors in the regulation of transmitter biosynthesis. Prog. Neuropsychopharmacol. 2: 139-158.

Ottersen, O. P. (1980) Afferent connections to the amygdaloid complex of the rat and cat. II. Afferents from the hypothalamus and the basal telencephalon. J. Comp. Neurol. 194: 267-289.

Ottersen, O.P. (1981) Afferent connections to the amygdaloid complex of the rat with some observations in the cat. III. Afferents from the lower brain stem. J. Comp. Neurol. 202: 335-356.

Ottersen, O. P. (1982) Connections of the amygdala of the rat. IV. Corticoamygdaloid and intraamygdaloid connections as studied with axonal transport of horseradish peroxidase. J. Comp. Neurol. 205: $30-48$.

Ottersen, O. P., and Y. Ben-Ari (1979) Afferent connections to the amygdaloid complex of the rat and cat. I. Afferents from the thalamus. J. Comp. Neurol. 187: 401-424.

Ouimet, C. C., P. E. Miller, H. C. Hemmings, Jr., S. I. Wallas, and P. Greengard (1984) Darpp-32, a dopamine- and adenosine $3^{\prime}: 5^{\prime}$ monophosphate-regulated phosphoprotein enriched in dopamine-innervated brain regions. J. Neurosci. 4: 111-124.

Palkovits, M. (1973) Isolated removal of hypothalamic or other brain nuclei of the rat. Brain Res. 59: 449-450.

Palkovits, M., and M. J. Brownstein (1983) Microdissection of brain areas by the punch technique. In Brain Microdissection Techniques, A. C. Cuello, ed., pp. 1-36, Wiley, New York.

Palkovits, M., J. M. Saavedra, R. M. Kobayashi, and M. Brownstein (1974) Choline acetyltransferase content of limbic nuclei of the rat. Brain Res. 79: 443-450.

Paxinos, G., and D. Bindra (1973) Hypothalamic and midbrain neural pathways involved in eating, drinking, irritability, aggression, and copulation in rats. J. Comp. Physiol. Psychol. 82: 1-14.

Pericic, D., and J. R. Walters (1976) Dopamine in substantia nigra and cortex after $\gamma$-butyrolactone treatment. J. Pharm. Pharmacol. 28: 527-530.

Roberts, G. W., P. L. Woodhams, J. M. Polak, and T. J. Crow (1982) Distribution of neuropeptides in the limbic system of the rat: The amygdaloid complex. Neuroscience 7:91-131.

Roffler-Tarlov, S., and A. M. Graybiel (1984) Weaver mutation has differential effects on the dopamine-containing innervation of the limbic and nonlimbic striatum. Nature 307: 62-66.

Roth, R. H. (1979) Dopamine autoreceptors: Pharmacology, function and comparison with post-synaptic dopamine receptors. Commun. Psychopharmacol. 3: 429-445.

Roth, R. H. (1984) CNS dopamine autoreceptors: Distribution, pharmacology and function. In Presynaptic Modulation of Postsynaptic Receptors in Mental Diseases, A. I. Salama, ed., pp. 27-53, New York Academy of Science, New York.

Roth, R. H., J. R. Walters, and G. K. Aghajanian (1973) Effects of impulse flow on the release and synthesis of dopamine in the rat striatum. In Frontiers in Catecholamine Research, vol. 11, E. Usdin and S. H. Snyder, eds., pp. 567-574, Pergamon, New York.

Saavedra, J. M., and J. Zivin (1976) Tyrosine hydroxylase and dopamine- $\beta$-hydroxylase: Distribution in discrete areas of the rat limbic system. Brain Res. 105: 517-524.

Saavedra, J. M., M. Brownstein, and M. Palkovits (1974) Serotonin distribution in the limbic system of the rat. Brain Res. 79: 437-441.

Saller, C. F., and A. I. Salama (1984) Dopamine synthesis in synaptosomes: Relation of autoreceptor function to $\mathrm{pH}$, membrane depolarization and intrasynaptosomal dopamine content. J. Neurochem. 43: 675-682.

Scatton, B. (1981) Differential changes in DOPAC levels in the hip- pocampal formation, septum and striatum of the rat induced by acute and repeated neuroleptic treatment. Eur. J. Pharmacol. 71:499-503.

Scatton, B., A. Dubois, M. L. Dubocovich, N. R. Zahniser, and D. Fage (1985) Quantitative autoradiography of ${ }^{3} \mathrm{H}$-nomifensine binding sites in rat brain. Life Sci. 36: 815-822.

Shibata, S., T. Yamamoto, and S. Ueki (1982) Differential effects of medial, central and basolateral amygdaloid lesions on four models of experimentally-induced aggression in rats. Physiol. Behav. 28: 289294.

Shiosaka, S., M. Sakanaka, S. Inagaki, E. Senba, Y. Hara, K. Takatsuki, H. Takagi, Y. Kawai, and M. Tohyama (1983) Putative neurotransmitters in the amygdaloid complex with special reference to peptidergic pathways. In Chemical Neuroanatomy, P. C. Emson, ed., pp. 359-389, Raven, New York.

Siegel, A. (1984) Anatomical and functional differentiation within the amygdala-behavioral state modulation. In Modulation of Sensorimotor Activity During Alterations in Behavioral States, R. Bandler, ed., pp. 299-323, Liss, New York.

Skirboll, L. R., A. A. Grace, and B. S. Bunney (1979) Dopamine autoand postsynaptic receptors: Electrophysiological evidence for differential sensitivity to dopamine agonists. Science $206: 80-82$.

Smith, R. C., C. A. Tamminga, and J. M. Davis (1977) Effect of apomorphine on schizophrenic symptoms. J. Neural Trans. 40:171176

Starke, K. (1981) Presynaptic receptors. Annu. Rev. Pharmacol. Toxicol. 21: 7-30.

Stephan, H., and O. J. Andy (1977) Quantitative comparison of the amygdala in insectivores and primates. Acta Anat. 98: 130-153.

Stevens, J. R. (1973) An anatomy of schizophrenia? Arch. Gen. Psychiatry 29: 177-189.

Stoof, J. C., and J. W. Kebabian (1981) Opposing roles for D-I and D-2 dopamine receptors in efflux of cyclic AMP from rat neostriatum. Nature 294: 366-368.

Swanson, L. W. (1982) The projections of the ventral tegmental area and adjacent regions: Combined fluorescent retrograde tracer and immunofluorescence study in the rat. Brain Res. Bull. 9: 321-353.

Ten Donkelaar, H. J., G. J. Lammers, and A. A. M. Bribnau (1979) Neurogenesis in the amygdaloid nuclear complex in a rodent (the Chinese hamster). Brain Res. 165: 348-353.

Tepper, J. M., S. J. Young, and P. M. Groves (1984) Autoreceptormediated changes in dopaminergic terminal excitability: Effects of increases in impulse flow. Brain Res. 309: 309-316.

Tissari, A. H., L. Atzori, and M. T. Galdieri (1983) Inhibition of dopamine synthesis in striatal synaptosomes by lisuride: Stereospecific reversal by (-)-sulpiride. Naunyn Schmiedebergs Arch. Pharmacol. 322: 89-92.

Ungerstedt, U. (1971) Stereotaxic mapping of the monoamine pathways in the rat brain. Acta Physiol. Scand. (Suppl.) 367: 1-48.

Walters, J. R., and R. H. Roth (1976) Dopaminergic neurons: An in vivo system for measuring drug interactions with presynaptic receptors. Naunyn Schmiedebergs Arch. Pharmacol. 296: 5-14.

Walters, J. R., R. H. Roth, and G. K. Aghajanian (1973) Dopaminergic neurons: Similar biochemical and histochemical effects of $\gamma$-hydroxy butyrate and acute lesions of the nigroneostriatal pathway. J. Pharmacol. Exp. Ther. 186: 630-639.

Westerink, B. H. C. (1985) Sequence and significance of dopamine metabolism in the rat brain. Neurochem. Int. 7: 221-227.

Westfall, T. C., L. Naes, and C. Paul (1983) Relative potency of dopamine agonists on autoreceptor function in various brain regions of the rat. J. Pharmacol. Exp. Ther. 224: 199-205. 